\title{
MECHANISM OF SEISMIC RESPONSE OF A PC CABLE-STAYED BRIDGE SUBJECTED TO A LONG-PERIOD SEISMIC EXCITATION
}

\author{
Gaku SHOJIㅁ, Jun KITAHARA², Atsushi KOJIMA³, Toshiyuki KANAKUBO4, \\ Katsuyuki SHIMIZU5 ${ }^{5}$ and Yuki SAKAI6 \\ ${ }^{1}$ Associate Professor, Graduate School of Systems and Information Engineering, University of Tsukuba \\ (1-1-1 Tennodai, Tsukuba, Ibaraki 305-8573, Japan) \\ E-mail: gshoji@kz.tsukuba.ac.jp \\ ${ }^{2}$ Bureau of Sewerage, Tokyo Metropolitan Government \\ (2-8-1 Nishi-Shinjuku, Shinjuku-ku, Tokyo 163-8001, Japan) \\ E-mail: Jun_Kitahara@member.metro.tokyo.jp \\ ${ }^{3}$ Graduate School of Systems and Information Engineering, University of Tsukuba \\ (1-1-1 Tennodai, Tsukuba, Ibaraki 305-8573, Japan) \\ E-mail: kojima@kz.tsukuba.ac.jp \\ ${ }^{4}$ Associate Professor, Graduate School of Systems and Information Engineering, University of Tsukuba \\ (1-1-1 Tennodai, Tsukuba, Ibaraki 305-8573, Japan) \\ E-mail: kanakubo@kz.tsukuba.ac.jp \\ ${ }^{5}$ Former Graduate Student, Graduate School of Systems and Information Engineering, University of Tsukuba \\ (1-1-1 Tennodai, Tsukuba, Ibaraki 305-8573, Japan) \\ ${ }^{6}$ Associate Professor, Graduate School of Systems and Information Engineering, University of Tsukuba \\ (1-1-1 Tennodai, Tsukuba, Ibaraki 305-8573, Japan) \\ E-mail: sakai@kz.tsukuba.ac.jp
}

\begin{abstract}
In this study, the mechanisms associated with the seismic response of a long-period structure when subjected to a long-period seismic excitation are clarified. A typical scale cable-stayed bridge with prestressed concrete girders (PC cable-stayed bridge) was selected for analysis. First, we simulated longperiod components of the ground motion at the site of the Ji-Lu Bridge, which was damaged in the 1999 Chi-Chi, Taiwan earthquake, and the damage of the bridge was assessed by nonlinear seismic analysis using the simulated ground excitations. Second, shaking table tests of a model PC cable-stayed bridge were carried out, in consideration of the similarity law, to clarify the mechanisms involved, focusing on the linear and nonlinear seismic responses of the tower and cables.
\end{abstract}

Key Words : long-period seismic excitation, long-period structure, PC cable-stayed bridge, seismic response analysis, shaking table test

\section{INTRODUCTION}

The infrastructure sustaining our socio-economic activity has been affected by recent severe earthquakes. These earthquakes are classified depending on the two distinct event mechanisms involved: plate boundary and inner slab earthquakes (far-field earthquakes), and active fault earthquakes (nearfield earthquakes). The former excite long-period and long-duration ground motion, and the latter excite ground motion that contains strong, shortduration impulse components. Although both types of earthquakes cause devastating damage to infra- structure because their resonant frequencies match the dominant frequencies of the ground motion, the damage to infrastructure caused by far-field earthquakes has been investigated more extensively. The reason for this is that large far-field earthquakes have occurred in recent years, such as the 2003 Tokachi-oki earthquake and the 2004 SumatraAndaman earthquake. In the Tokachi-oki earthquake, a terrible fire occurred at an oil tank located on the Tomakomai Plain due to sloshing of its contents resulting from the long-period seismic excitation. The source of the Sumatra-Andaman earthquake is estimated to be a region about $1000 \mathrm{~km}$ wide from 
north to south, with a fault length of about $560 \mathrm{~km}$, a fault width of about $150 \mathrm{~km}$, and a maximum dislocation of about $13.9 \mathrm{~m}$. In addition to these previous far-field earthquakes, the possibility of a Tokai, Toh-Nankai, or Nankai Earthquake in the next 30 years is considered to be very high. Since far-field earthquakes excite long-period and long-duration ground motion, long-period structures subjected to their seismic excitation might be severely damaged. In terms of the definition of the range of the 'longperiod' and 'long-duration', it has been established from the field of strong motion seismology that the fundamental period of a ground motion reaches to more than about $2.0 \mathrm{sec}$ or $2.5 \mathrm{sec}$ and the longperiod components contain dominantly in the ground motion, and in addition the duration of the main and subsequent excitation becomes more than several minutes that correspond to more than 3.0 minutes or 4.0 minutes. ${ }^{1)}$

On the other hand, large active-fault earthquakes, such as the 1999 Chi-Chi, Taiwan earthquake, excite long-period components from $1.0 \mathrm{sec}$ to $2.0 \mathrm{sec}$ due to the large rupture of the fault. In this earthquake, strong ground motion was observed due to the rupture of the Chelungph Fault, which is about $80 \mathrm{~km}$ wide from north to south and about $40 \mathrm{~km}$ wide from east to west; in fact, ground surface movement of several meters occurred along the fault A large cable-stayed bridge constructed of prestressed concrete girders (PC cable-stayed bridge) located about $6 \mathrm{~km}$ from the epicenter was damaged by the seismic excitation; for example, the cover concrete of the longitudinal reinforcements on its tower bottom spalled off. ${ }^{2), 3), 4)}$ This was an important opportunity to analyze the bridge in order to understand the damage mechanisms of long-period structures when subjected to long-period components of a ground motion, because there are few recorded historical incidents of this type.

Many researchers are involved in computer-based simulations to predict long-period ground motion due to a large far-field earthquake. Kamae et al., ${ }^{5)}$ for instance, carried out a simulation of the ground motion that would be excited in the Osaka Plain due to the anticipated Nankai earthquake using the finite differential method. The simulation of long-period ground motion with a period of more than $2.0 \mathrm{sec}$ or $2.5 \mathrm{sec}$ agreed well with observatory records; therefore, these simulated ground motions may be useful as input ground motions in conducting seismic response analyses of long-period structures.

The seismic damage of a structure subjected to this simulated ground motion could be assessed because the finite differential method simulates the effects of 1) the rupture process, 2) the underground structure, and 3) the ground surface. Otsuka et al. ${ }^{6}$ evaluated long-period ground motion at the site of a planned long-span bridge structure in Tokyo Bay by adopting the same method as described above. Komori et $a l^{7)}$ clarified the effectiveness of strengthening the structural components of large bridges in the Metropolitan Expressway by using their own simulated long-period ground motion.

Many researchers are involved in theoretical and numerical simulations to understand the mechanisms associated with the seismic response of cablestayed bridges. For instance, Nazmy and AbdelGhaffar ${ }^{8), 9)}$ developed a theoretical evaluation model of the seismic response of large cable-stayed bridges, and they conducted numerical studies based on their theory.

In contrast to these theoretical and numerical studies, however, the seismic responses of cablestayed bridges have not been sufficiently studied experimentally. Vilaverde and Martin ${ }^{10)}$ carried out seismic shaking table tests on models to evaluate the effectiveness of seismic control devices for cablestayed bridges. Kawashima et al. ${ }^{11)}$ evaluated the damping mechanism of cable-stayed bridges in experimental studies using 1/150-scale models. Kitazawa et al. ${ }^{12)}$ investigated the effectiveness of dampers installed on the Higashi-Kobe Bridge by shaking table tests.

Despite the abundance of data from these studies, the mechanisms involved in the seismic response of cable-stayed long-period bridges when subjected to a long-period component of ground motion have not yet been sufficiently clarified from theoretical and experimental points of view. Especially, no experimental studies to clarify the seismic response of a cable-stayed bridge when subjected to a long-period ground motion by considering the similarity ratios of a bridge model with a prototype cable-stayed bridge, have ever tried.

In view of the above, in this study the mechanisms associated with the seismic response of a PC cable-stayed bridge when subjected to a long-period ground motion were clarified by conducting seismic response analyses and shaking table tests considering the similarity law. This study defined the 'longperiod' of a ground excitation as the period of more than $2.0 \mathrm{sec}$ or $2.5 \mathrm{sec}$ referring the previous definition. The natural period of the subject long-period structures was from $2.0 \mathrm{sec}$ to $3.0 \mathrm{sec}$. The longperiod components of the simulated ground motion in the 1999 Chi-Chi, Taiwan earthquake and the simulated long-period ground motions in the anticipated Nankai earthquake were used as the input gro- 


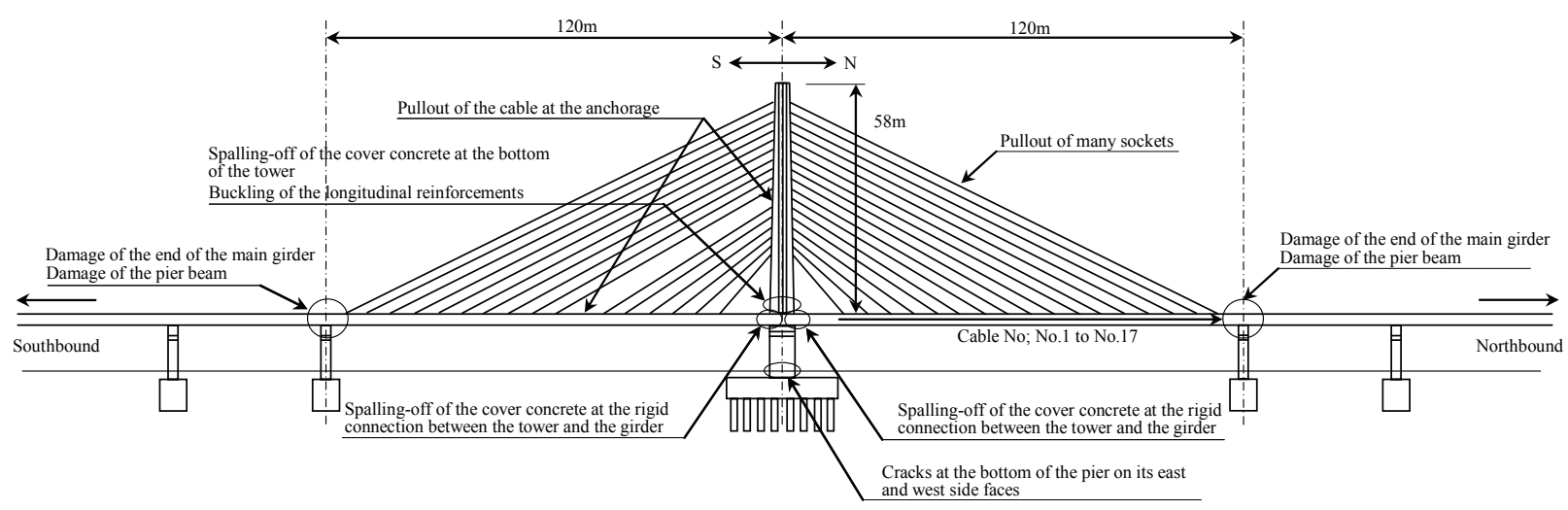

Fig. 1 Damage to the Ji-Lu Bridge. ${ }^{4)}$

Table 1 Structural characteristics of the Ji-Lu Bridge.

\begin{tabular}{|l|l|}
\hline Structural type & Two-spanned PC cable-stayed bridge \\
\hline Total length / span & $240 \mathrm{~m} / 120 \mathrm{~m}$ \\
\hline Height of tower & $58 \mathrm{~m}$ \\
\hline Tower & Hollow type RC \\
\hline Pier & RC, elliptic section of $6.0 \mathrm{~m} \times 6.3 \mathrm{~m}$ \\
\hline Foundation & Pile foundation \\
\hline
\end{tabular}

Table 2 Tensions of cables.

\begin{tabular}{|c|c|c|c|}
\hline Cable No. & Tension (MN) & Cable No. & Tension (MN) \\
\hline 1 & 7.54 & 10 & 5.72 \\
\hline 2 & 6.15 & 11 & 5.84 \\
\hline 3 & 5.33 & 12 & 6.54 \\
\hline 4 & 5.06 & 13 & 6.05 \\
\hline 5 & 5.06 & 14 & 6.28 \\
\hline 6 & 5.15 & 15 & 6.54 \\
\hline 7 & 5.30 & 16 & 6.53 \\
\hline 8 & 5.44 & 17 & 5.51 \\
\hline 9 & 5.58 & \multicolumn{3}{|l}{} \\
\hline
\end{tabular}

und motions in the numerical analyses and the shaking table tests. First, we analyzed the seismic damage to the Ji-Lu Bridge in the 1999 Chi-Chi, Taiwan earthquake using the simulated long-period ground motions, and second, the mechanisms associated with the seismic response of a PC cable-stayed bridge when subjected to the simulated long-period ground motions in the 1999 Chi-Chi, Taiwan earthquake and the anticipated Nankai earthquake, were clarified by conducting shaking table tests.

\section{SIMULATION OF INPUT GROUND MOTION AT THE SITE OF THE JI- LU BRIDGE DUE TO THE 1999 CHI- CHI, TAIWAN EARTHQUAKE}

\section{(1) Ji-Lu bridge and its seismic damage}

The subject bridge is the Ji-Lu Bridge, a two-span PC cable-stayed bridge located about $6 \mathrm{~km} \mathrm{S30W}$ of the epicenter of the 1999 Chi-Chi, Taiwan earthquake. Its longitudinal direction is from north to south. Table 1 shows its structural characteristics. The tower and the pier are constructed of reinforced concrete (RC) columns and the sectional area of the tower is $4.0 \mathrm{~m} \times 3.0 \mathrm{~m}$ at the top, increasing to 6.0 $\mathrm{m} \times 3.0 \mathrm{~m}$ at the bottom. The area ratio $\rho_{l}$ of the longitudinal reinforcements and the volume ratio $\rho_{s}$ of the hoop reinforcements are respectively $2.88 \%$ and $4.73 \%$ at the top of the tower, and $2.94 \%$ and $14.17 \%$ at the bottom of the tower. The cross section of the pier is elliptic and its sectional area is 6.0 $\mathrm{m} \times 6.3 \mathrm{~m}$. The area ratio $\rho_{l}$ of the longitudinal reinforcements and the volume ratio $\rho_{s}$ of the hoop reinforcements of the pier are $1.10 \%$ and $1.89 \%$, respectively. The bridge cables are of the 2-plain type and the total number of cables is 68 . Table 2 shows the tension strengths of the cables. The cable numbers indicated in Table 2 correspond to those indicated in Fig. 1 described below.

Fig. 1 shows the damage to the Ji-Lu Bridge. ${ }^{4}$ The bridge was under construction during the event and four precast panels near the rigid connection between the tower and the deck were not yet built. The cover concrete on the east and west sides at the bottom of the tower spalled off and the longitudinal reinforcements were buckled. Shear cracks occurred in the beams of the piers because the deck moved in the transverse direction. The reason for this damage is that the bridge was subjected to strong ground motion in the transverse direction, namely, from east to west. Moreover, the deck concrete at the joint section between the deck and the tower spalled off, and local buckling of the longitudinal bars in the deck occurred at the south part of the joint section. The diagonal cables at the anchorage section were pulled out.

Kosa et $a l^{3)}$ and Tai and Liou ${ }^{13)}$ analyzed the vibrational modes of the bridge, as shown in Table 3. The first mode is predominant in the transverse direction from east to west, the second mode is the anti-symmetric longitudinal vibration from north to 
Table 3 Natural periods of the Ji-Lu Bridge. ${ }^{3), 13)}$

\begin{tabular}{|c|c|c|}
\hline Mode No. & $\begin{array}{l}\text { Natural period, from } \\
\text { reference 3 }(\mathrm{sec})\end{array}$ & $\begin{array}{l}\text { Natural period, from } \\
\text { reference 13 }(\mathrm{sec})\end{array}$ \\
\hline 1 & 1.99 & 2.28 \\
\hline 2 & 1.66 & 1.80 \\
\hline 3 & 1.19 & 1.05 \\
\hline 4 & 1.08 & 1.03 \\
\hline
\end{tabular}

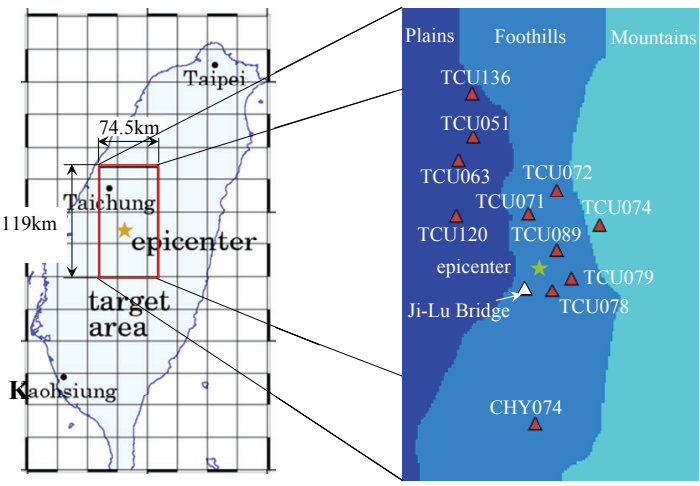

Fig. 2 The analysis region.

south, the third mode is the vertical vibration, and the fourth mode is the sway mode in the longitudinal direction from north to south.

\section{(2) Simulation of input ground motion at the site of the $\mathrm{Ji}-\mathrm{Lu}$ bridge}

In this section we simulate the seismic ground excitation at the site of the Ji-Lu Bridge, which is used as the input ground motion when conducting the seismic dynamic analyses and the shaking table tests. Because the ground excitation at the site of the Ji-Lu Bridge was not recorded during the 1999 ChiChi, Taiwan earthquake, the dependence of the long-period components of the simulated ground excitation with the damage to the bridge can be obtained by doing seismic dynamic analyses with the simulated ground excitation as the input ground motion for the Ji-Lu Bridge. As well as in the seismic response analyses, in the shaking table tests, the simulated ground excitations of the anticipated Nankai earthquake, computed by Kamae et al., , $^{5}$ are used. They adopted hybrid method to simulate both short-period components and long-period ones of the subject ground motion, then we used long-period components of the simulated ground excitations of the anticipated Nankai earthquake.

\section{a) Analysis region}

The 1999 Chi-Chi, Taiwan, Earthquake of $M_{w}=$ 7.6 occurred on September 21, 1999, with its epicenter in the town of Chi-Chi, Taiwan. The Chelungph Fault ruptured for about $80 \mathrm{~km}$ from north to south, resulting in severe ground dislocation. ${ }^{14)}$ From the rupture size of the Chelungph Fault, we set an analysis region $119 \mathrm{~km}$ wide from north to south and $74.5 \mathrm{~km}$ wide from east to west in the

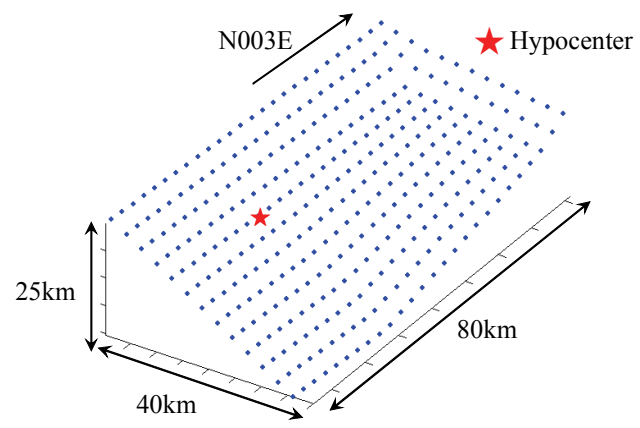

Fig. 3 Fault source model. ${ }^{14)}$

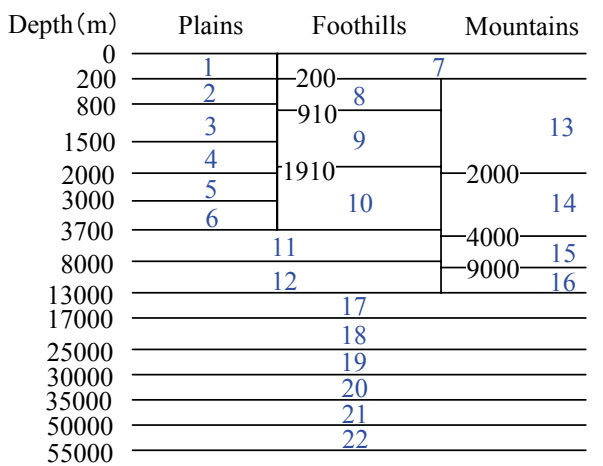

Fig. 4 Underground structure model (modified the results from references 14,15 ).

plain, as shown in Fig. 2. The locations of the epicenter, the subject bridge, and the observatory stations are shown in Fig. 2.

\section{b) Source model}

The fault source model derived by Sekiguchi and Iwata $^{14)}$ was used, as shown in Fig. 3. From their model the fault sources were $80 \mathrm{~km}$ wide from north to south, $40 \mathrm{~km}$ wide from east to west, and $25 \mathrm{~km}$ deep. The rupture surface of the fault was classified into $26 \times 13$ subfaults, and then each subfault was modeled as a point source. The rupture process of each point source was modeled as eight time windows. The width of each window was $2 \mathrm{sec}$, and the phase difference between two successive windows was $1.2 \mathrm{sec}$. The derivative of the smoothed ramp function was used for the source time function.

\section{c) Underground structure}

Chung and $\mathrm{Yeh}^{15)}$ evaluated the velocity structure in the region from 22.7 to 23.7 degrees north latitude and from 120.0 to 121.0 degrees east longitude using a dispersion analysis. The subject underground structure in the region shown in Fig. 2 was assumed to be the same as the above structure used by Chung and Yeh. Fig. 4 and Table 4 show the underground structure in the section from east to west. The boundary lines between the mountains and the foothills and between the foothills and the plains were determined based on topographical maps of the region. ${ }^{16)}$ The surface structure in the plains down to $200 \mathrm{~m}$ beneath the surface was estimated as shown in Table $\mathbf{4}$ from the velocity struc- 
Table 4 Parameters of the velocity structure (modified the results from references 14, 15).

\begin{tabular}{|r|r|r|r|r|}
\hline Layer No. & $V p(\mathrm{~m} / \mathrm{s})$ & $\begin{array}{c}V s \\
(\mathrm{~m} / \mathrm{s})\end{array}$ & Mass density $\left(\mathrm{kg} / \mathrm{m}^{3}\right)$ & $Q(\mathrm{~Hz})$ \\
\hline 1 & 1000 & 500 & 1600 & 90 \\
\hline 2 & 1980 & 900 & 2100 & 100 \\
\hline 3 & 2900 & 1320 & 2200 & 100 \\
\hline 4 & 3476 & 1580 & 2300 & 150 \\
\hline 5 & 3484 & 1960 & 2400 & 200 \\
\hline 6 & 4551 & 2560 & 2500 & 250 \\
\hline 7 & 2000 & 1000 & 1900 & 90 \\
\hline 8 & 2880 & 1550 & 2000 & 100 \\
\hline 9 & 3150 & 1700 & 2050 & 200 \\
\hline 10 & 4370 & 2500 & 2300 & 250 \\
\hline 11 & 5130 & 2850 & 2400 & 250 \\
\hline 12 & 5900 & 3300 & 2600 & 270 \\
\hline 13 & 3480 & 1960 & 2400 & 200 \\
\hline 14 & 4480 & 2620 & 2500 & 250 \\
\hline 15 & 5250 & 3030 & 2600 & 250 \\
\hline 16 & 5830 & 3350 & 2650 & 270 \\
\hline 17 & 6210 & 3610 & 2700 & 300 \\
\hline 18 & 6410 & 3710 & 2750 & 350 \\
\hline 19 & 6830 & 3950 & 2800 & 400 \\
\hline 20 & 7290 & 4210 & 3000 & 500 \\
\hline 21 & 7770 & 4490 & 3100 & 500 \\
\hline 22 & 8050 & 4680 & 500 & 500 \\
\hline & & & & \\
\hline & & & 2600 \\
\hline
\end{tabular}

Table 5 Numerical conditions.

\begin{tabular}{|l|c|c|}
\hline \multirow{2}{*}{\multicolumn{1}{|c|}{ Conditions }} & \multicolumn{2}{c|}{ Values } \\
\cline { 2 - 3 } & Region 1 & Region 2 \\
\hline Upper frequency limit & \multicolumn{2}{|c|}{$0.5 \mathrm{~Hz}$} \\
\hline No. of sample points & \multicolumn{2}{|c|}{12000} \\
\hline Time integration & \multicolumn{2}{|c|}{$0.005 \mathrm{sec}$} \\
\hline Time duration & $\begin{array}{c}\text { Horizontal } \\
200 \mathrm{~m}\end{array}$ & Horizontal \\
\hline \multirow{2}{*}{\begin{tabular}{l} 
Mesh size \\
\cline { 2 - 3 }
\end{tabular}} & $\begin{array}{c}\text { Depth } \\
100 \mathrm{~m}\end{array}$ & $\begin{array}{c}\text { Depth } \\
300 \mathrm{~m}\end{array}$ \\
\hline $\begin{array}{l}\text { Depth at the boundary between } \\
\text { region 1 and region 2 }\end{array}$ & \multicolumn{2}{|c|}{$24 \mathrm{~km}$} \\
\hline $\begin{array}{l}\text { No. of mesh grids of absorbing } \\
\text { boundary }\end{array}$ & 60 & 20 \\
\hline $\begin{array}{l}\text { Damping ratio of absorbing } \\
\text { boundary }\end{array}$ & 0.005 & 0.015 \\
\hline
\end{tabular}

ture obtained from the microwave survey by Tokimatsu and Sekiguchi. ${ }^{17)}$

\section{d) Numerical algorithm: finite differential method}

Among the numerous finite differential algorithms available, in this study we adopted the one proposed by Aoi and Fujiwara, ${ }^{18), 19)}$ which is a fourth-order approximation for the spatial derivative and a second-order one for the time derivative with discontinuous grids.

The spatial region simulated was $119 \mathrm{~km}$ wide from north to south, $74.5 \mathrm{~km}$ wide from east to west, and $55 \mathrm{~km}$ deep, including the absorbing boundary. Table 5 shows the parameters used in the numerical simulation. The frequency limit was set to $0.5 \mathrm{~Hz}$ because we are concerned only with long-period components of seismic excitations of more than 2.0

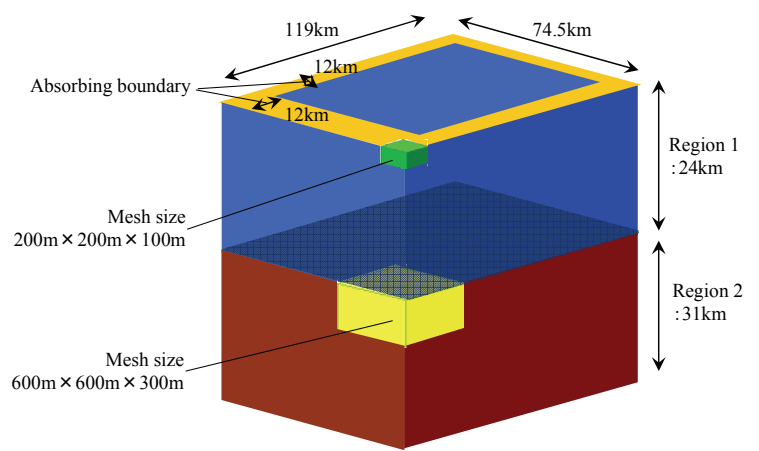

Fig. 5 Spatial region for simulation.

sec.

To guarantee numerical stability in the explicit approximation of the wave equation, it is necessary to restrict the wavefront propagation in a unit time step $\Delta t$ to a unit grid. For grid distance $h$, the necessary condition for numerical stability in the finite differential scheme is: ${ }^{20)}$

$$
\Delta t<0.495 \frac{h}{V_{\max }}
$$

where $V_{\max }$ is the maximum wave velocity. For the reason described above, the time step $\Delta t$ was set to $0.005 \mathrm{sec}$ and the time duration to be simulated was set to $60 \mathrm{sec}$ shown in Table 5.

Levander ${ }^{21)}$ indicated that a grid distance $h$ of less than one-fifth of the simulated wave length is required in the fourth-order approximation of the finite differential scheme. It has also been shown that the numerical damping and dispersion become stronger when the analyzed wave length becomes much shorter than one-fifth. ${ }^{22), 23)}$ As shown in Table 4 , the $\mathrm{S}$ wave length in layer 1 was a minimum of $500 \mathrm{~m}\left(V_{S}=500 \mathrm{~m} / \mathrm{s}\right)$. In addition, considering the frequency limit of $0.5 \mathrm{~Hz}$, the analyzed wave length was $1000 \mathrm{~m}$. Hence, the grid distances in the region 1 in the $x$ direction and the $y$ direction, that are horizontal directions, were the same, namely $200 \mathrm{~m}$. The grid distance in the region 1 in the $z$ direction, that is vertical direction, was set to $100 \mathrm{~m}$. The reason for this is that the numerical accuracy is strongly dependent upon the mesh size in the $z$ direction. The discrepancy of the phase between the simulated waveforms and the observed waveforms became larger when the mesh size in the $z$ direction was set to $200 \mathrm{~m}$ compared to when it was set to 100 $\mathrm{m}$.

In the Aoi and Fujiwara method, discontinuous mesh grids are defined to reduce the CPU memory required for the simulation. As shown in Fig. 5, region 1, in which the grid size is set to be smaller, is suitable for the complex surface structure and region 2 , in which the grid size is set to be larger, is suit- 


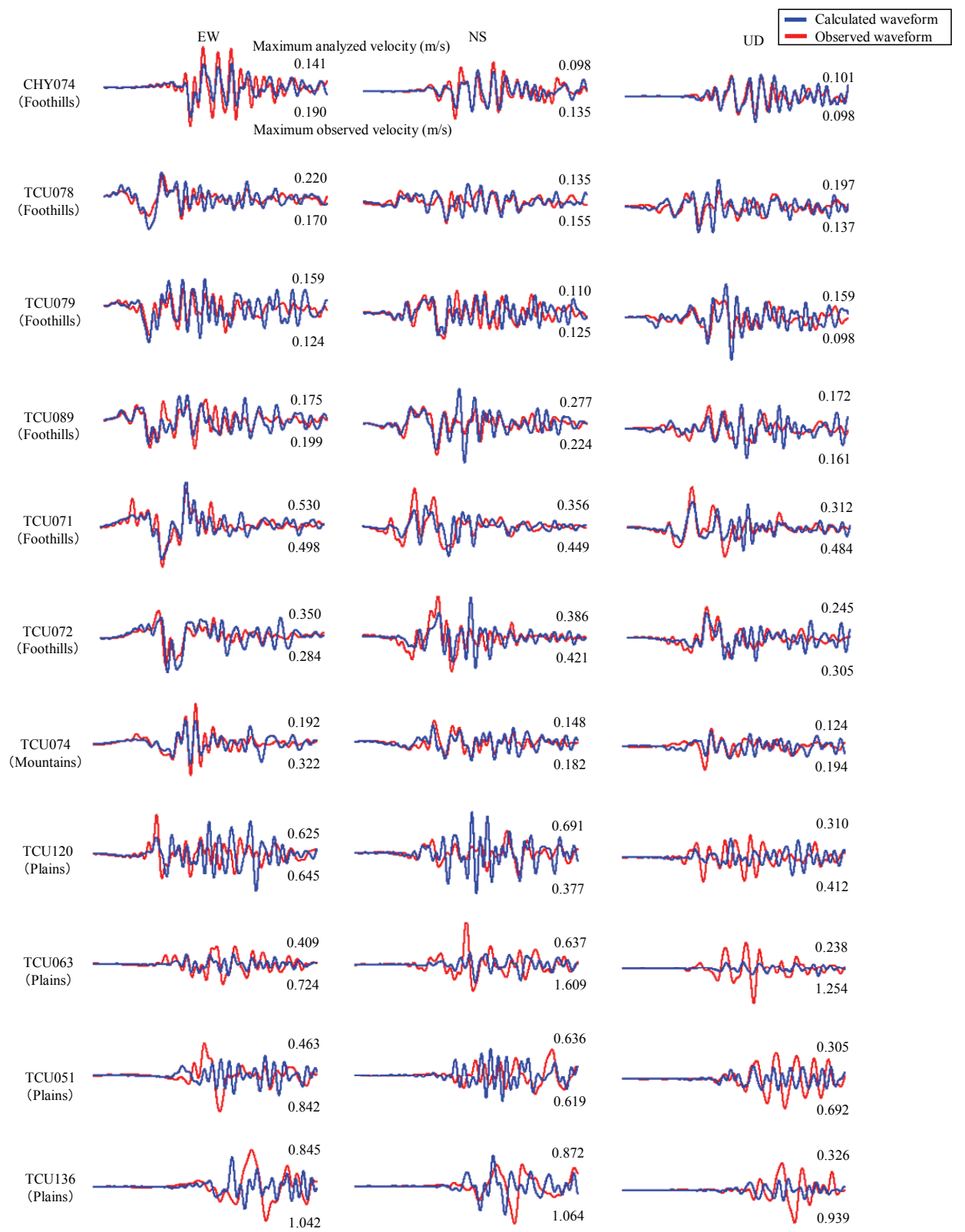

Fig.6 Comparison of the simulated waveforms with the observatory records.

able for the deeper underground structure. The grid size in region 2 was set to be 3 times larger than that in region 1. Since the depth of the fault source was about $24 \mathrm{~km}$ beneath the ground surface, the depth of the discontinuous surface between region 1 and region 2 was set to be $24 \mathrm{~km}$ beneath the ground surface. The absorbing boundary was based on the one proposed by Cerjan et $a l^{24)}$ and the nonreflection one proposed by Clayton and Engquist. ${ }^{25}$ The number of mesh grids and the damping ratios of the absorbing boundary were set by referring to the numerical study of Aoi and Fujiwara ${ }^{19)}$, as shown in Table 5.
(3) Simulation of the seismic excitation

a) Comparison of the simulated waveforms with the observatory records

The simulated waveforms were compared with the observatory records of the Central Weather Bureau $(\mathrm{CWB}),{ }^{26)}$ as shown in Fig. 6. Eleven records were used in the comparison. All simulated and observed waveforms were filtered by a band-pass filter from $2.0 \mathrm{sec}$ to $20.0 \mathrm{sec}^{14), 27)}$ The seven simulated waveforms at observatory stations CHY074, TCU078, TCU079, TCU089, TCU071, TCU072, and TCU074 agreed well with the observed records in terms of the accuracy of the amplitude and phase of the waveforms. To prove the agreement, the Fourier transforms of above seven simulated waveforms and the corresponding observed ones to the frequency domain were performed. The agreement as- 


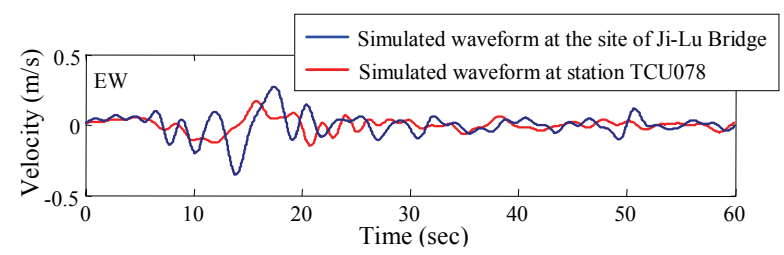

(a) EW component

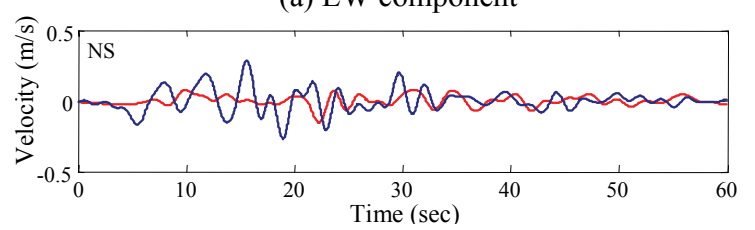

(b) NS component

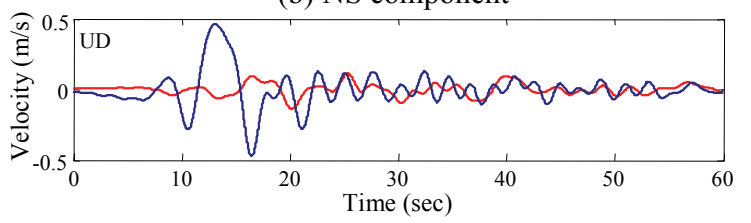

(c) UD component

Fig. 7 Comparison between the simulated waveforms at the site of the Ji-Lu Bridge and those at station TCU078.

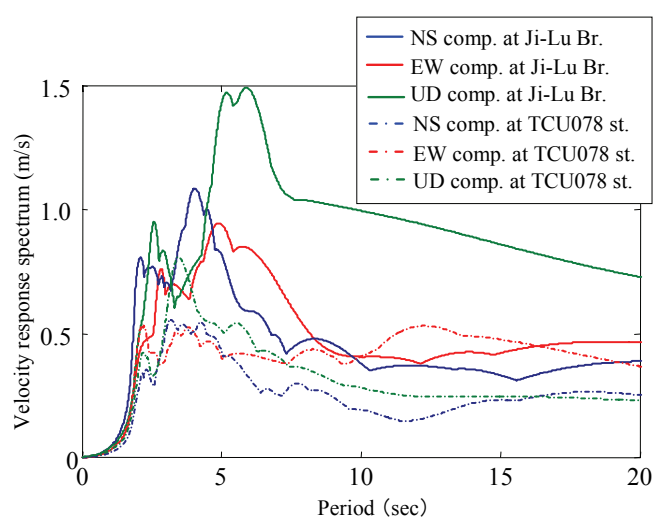

Fig. 8 Comparison of the velocity response spectra with a damping ratio of 0.05 between the simulated waveforms at the site of the $\mathrm{Ji}-\mathrm{Lu}$ Bridge and those at station TCU078.

sociated with the shape and trend of the Fourier amplitude spectra and the Fourier phase spectra obtained from the simulated waveforms and those from the observed ones was confirmed. These stations are located in the central part and the south part of the simulated region, on the foothills and the mountains. In contrast, the four simulated waveforms at stations TCU120, TCU063, TCU051, and TCU136 disagreed with the observed records in terms of the accuracy of the phase. These stations are located in the north part of the simulated region, on the plains. We hypothesize three main reasons for these results: the values of the $\mathrm{S}$ wave velocity and the $\mathrm{P}$ wave velocity in the plains were not reasonable; the source model in the north part of the simulated spatial region was not accurate and the grid size in the surface structure in the plain was large. The second reason is related to the fault rupture in the north part, which was larger than that in

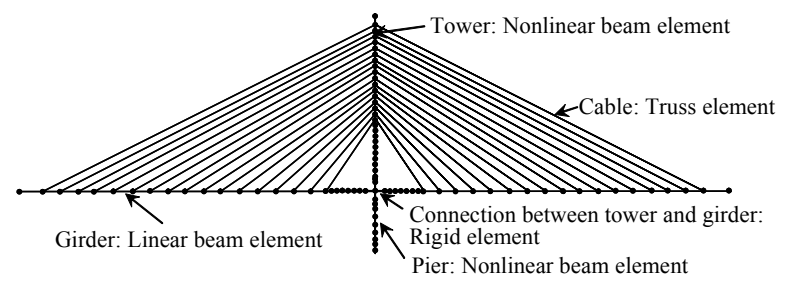

Fig. 9 3D frame model of the Ji-Lu Bridge.

the central and south parts, and also to the fact that the fault rupture in the north part was skewed. The third reason is related to the upper limit of the wave length in the plain, which was smaller than that in the foothills and the mountains.

\section{b) Simulation of the ground excitation at the site of the Ji-Lu bridge}

The accuracy of the simulated ground excitation in the foothills and the mountains was verified from Fig. 6. We simulated the ground excitation at the site of the Ji-Lu Bridge, which is located in the foothills. Fig. 7 shows a comparison of the simulated ground excitation at the site of the $\mathrm{Ji}-\mathrm{Lu}$ Bridge with the simulated one at station TCU078, which is located about $7.5 \mathrm{~km}$ from the bridge and in the foothills. Fig. 8 shows their velocity response spectra with a damping ratio of 0.05 .

From Fig. 7, the amplitudes and phases were found to differ between the simulated waveforms at the site of the Ji-Lu Bridge and those at station TCU078, and from Fig. 8, the velocity response based on those waveforms also to differ by factors of two to three in the period from $2.0 \mathrm{sec}$ to $7.0 \mathrm{sec}$. The reason for above difference is that the distance of the bridge and the station TCU078 is about $7.5 \mathrm{~km}$ and the wave propagation depending on the fault rupture process based on the Fig. 3 differs between the two sites.

\section{PRELIMINARY SEISMIC RESPONSE ANALYSIS OF THE JI-LU BRIDGE BEFORE SHAKING TABLE TESTS}

\section{(1) Model of the Ji-Lu bridge}

The seismic response of the Ji-Lu Bridge when subjected to the simulated seismic excitation derived in the previous section was analyzed. The bridge was modeled by the 3 dimensional (3D) frame model shown in Fig. 9. Nonlinear beam elements were adopted to model the tower and the pier, and the moment-versus-curvature relationship was assumed to be the idealized Takeda hysteresis model ${ }^{28)}$ The values of the moment and the curvature at the crack, the yielding, and the ultimate points were determined by referring to the research 


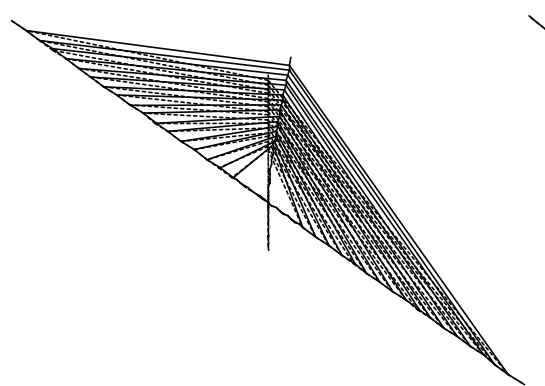

(a) 1 st mode

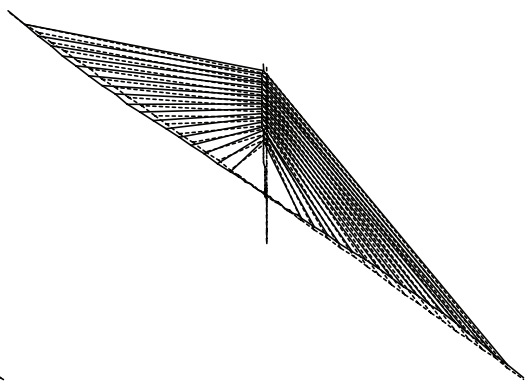

(b) 2nd mode

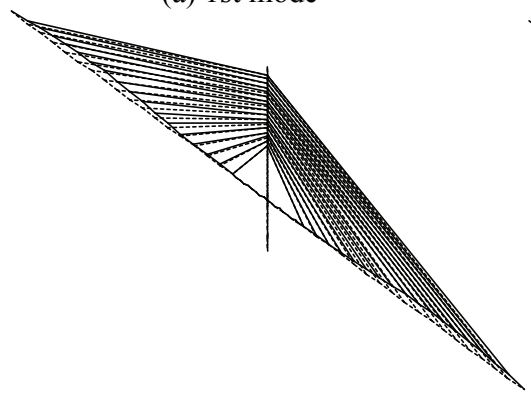

(c) 3rd mode

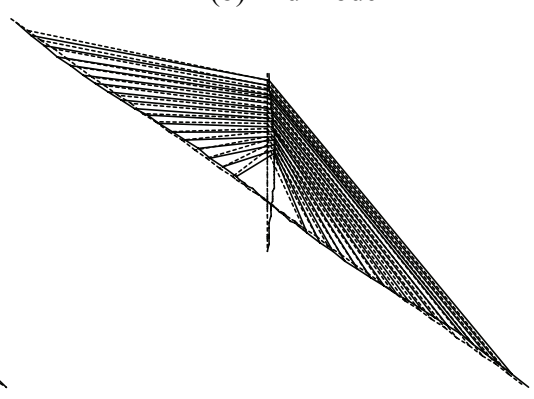

(d) 4th mode

Fig. 10 Mode shapes of the numerical model of the Ji-Lu Bridge.

of Abe. ${ }^{29)}$ The ratio of the unloading stiffness to the initial stiffness was assumed to be 0.4 . Because the sectional area of the tower varied gradually from the top to the bottom, the section of the tower was modeled by three idealized sections at the top, middle, and bottom.

A linear beam element was used to model the main girder, and truss elements having only tension stiffness were used to model the cables. The joint connection between the tower and the main girder was modeled by a rigid element. The mass of each cable was divided into the mass at the end connected to the tower and the mass at the other end connected to the main girder. The values of the modulus of elasticity, the moment of inertia, and the torsion constants of the pier, the main girder, and the cables were determined by referring to the results of Tasaki et $a l^{4)}$ The motion of the foundation was idealized by using a model including a sway spring, a rotation spring, and their coupled spring elements.

The longitudinal displacement and the moment with respect to the transverse axis at both ends of the main girder were free, and the others were fixed.

The idealized damping matrix in the equation of motion was obtained using the Rayleigh damping matrix. The constants in the summation of mass matrix and stiffness matrix were defined using the frequencies in the 1 st and 8 th modes, in which modal damping ratios are assumed to be the same of 0.02 . Table 6 and Fig. 10 show the natural periods and mode shapes of the numerical model of the bridge obtained from the modal analysis. The first and second modal periods (symmetry transverse mode and anti-symmetry longitudinal mode) shown in Table 6 are more similar to those with the model derived by
Table 6 Natural periods and mode shapes of the numerical model of the Ji-Lu Bridge.

\begin{tabular}{|c|c|l|}
\hline Mode No. & Natural period (sec) & \multicolumn{1}{|c|}{ Mode shape } \\
\hline 1 & 2.005 & Symmetry, TR dir. \\
\hline 2 & 1.447 & Anti-symmetry, LG dir. \\
\hline 3 & 0.637 & Symmetry, UD dir. \\
\hline 4 & 0.573 & Anti-symmetry, LG dir. \\
\hline 5 & 0.400 & Symmetry, TR dir. \\
\hline 6 & 0.373 & Anti-symmetry, LG dir. \\
\hline 7 & 0.361 & Symmetry, UD dir. \\
\hline 8 & 0.230 & Anti-symmetry, LG dir. \\
\hline 9 & 0.217 & Symmetry, UD dir. \\
\hline 10 & 0.157 & Anti-symmetry, LG dir. \\
\hline
\end{tabular}

(TR: Transverse, LG: Longitudinal, UD:Vertical)

Kosa et $a l^{3)}$ than those with the model derived by Tai and Liou ${ }^{13)}$ (refer Table 3). The third and fourth modal shapes (symmetry vertical mode and antisymmetry longitudinal mode) show close correspondence between our model and the models by Kosa et al., and Tai and Liou, but there are the differences between those modal periods shown in Table 6 and those by Kosa et al., and Tai and Liou, that become about $0.4 \mathrm{sec}$. The reason of this is that in our model, previously mentioned, the section of the tower was modeled by three idealized sections at the top, middle, and bottom under the structural condition with the sectional area of the tower varied from the top to the bottom.

\section{(2) Seismic damage assessment of the Ji-Lu Bridge}

The displacement and the acceleration at the top of 

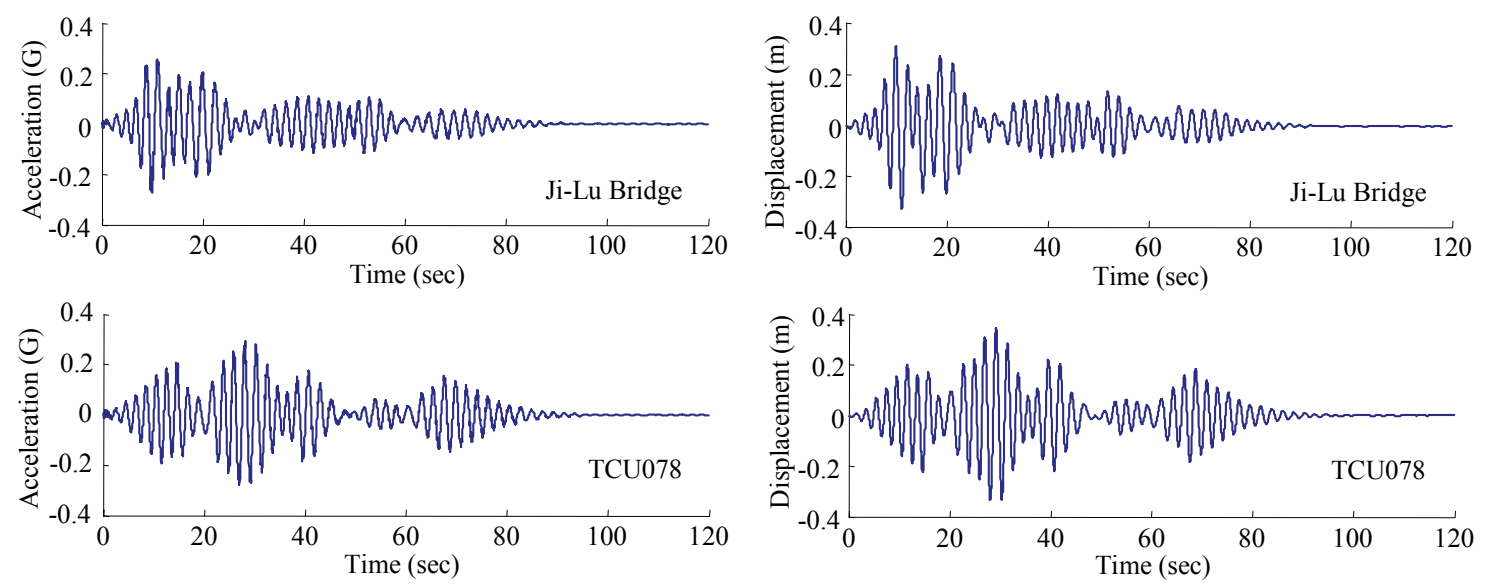

(a) Acceleration response

(b) Displacement response

Fig. 11 Acceleration and displacement responses at the top of the tower in the transverse direction when subjected to the simulated excitation at the site of the Ji-Lu Bridge and that at station TCU078.

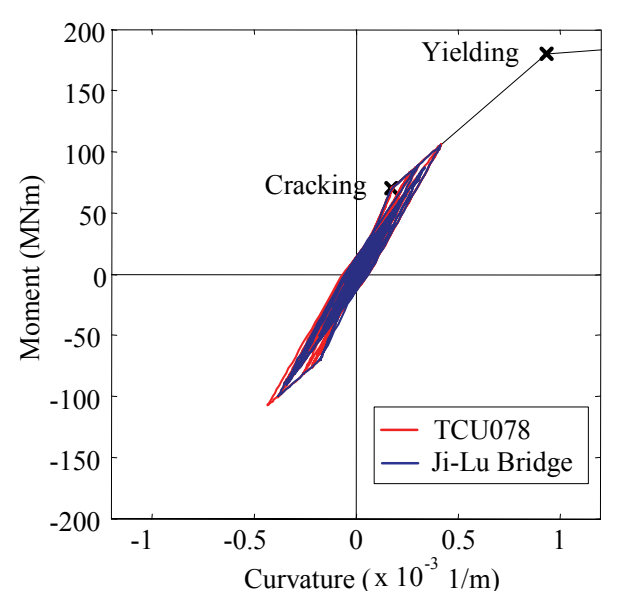

Fig. 12 Moment-versus-curvature relationship when subjected to the simulated excitation at the site of the $\mathrm{Ji}-\mathrm{Lu}$ Bridge and that at station TCU078.

the tower in the transverse direction were computed as shown in Fig. 11 when the bridge was subjected to the simulated seismic excitation at the site of the bridge and that at station TCU078. Fig. 12 shows the moment-versus-curvature relationship at the bottom of the tower. Fig. 12 indicates that damage beyond the crack level occurred at the bottom of the tower when subjected to both excitations. However, yielding-level damage did not occur at the bottom of the tower, although yielding of the longitudinal reinforcements and spalling-off of the cover concrete actually occurred in the Ji-Lu Bridge. In addition, despite the difference between the simulated excitation at the site of the Ji-Lu Bridge and that at station TCU078, as shown in Figs. 7 and $\mathbf{8}$, the momentversus-curvature relationships for those cases did not differ. The reason for this is that there is a slight difference of the velocity response spectra at the period of $2.005 \mathrm{sec}$, which is the $1 \mathrm{st}$ natural period of the bridge, as shown in the site of the $\mathrm{Ji}-\mathrm{Lu}$ Bridge contained more long-period components beyond $2.0 \mathrm{sec}$ than that at station TCU078. Hence, the seismic responses when subjected to the simulated excitation at the site of the Ji-Lu Bridge and that at station TCU078 were almost the same around the period of $2.005 \mathrm{sec}$.

\section{SHAKING TABLE TESTS}

\section{(1) Bridge model and experimental setup}

a) Design of the bridge model

To clarify the mechanisms associated with the seismic response of a PC cable-stayed bridge when subjected to a long-period seismic excitation, we selected a typical PC cable-stayed bridge with a natural period from $2.0 \mathrm{sec}$ to $3.0 \mathrm{sec}$, such as the $\mathrm{Ji}$ $\mathrm{Lu}$ Bridge shown in the previous sections, as the model bridge for the series of shaking table tests. We considered the following three requirements for the design of the bridge model:

i. The similarity ratio of acceleration should be set to 1.0 because it is difficult to control gravitational acceleration in the experiments.

ii. The bridge model should be simple in terms of its fabrication and construction.

iii. The model should be as large as possible to eliminate the effects of irregularity in its configuration and variations in the properties of the materials used to build the bridge model.

Based on these requirements, the similarity ratios of the model with respect to the prototype bridge were determined as shown in Table 7. The similarity ratio of the length was set to 100 by considering the size of the shaking table and the ease of constructing the model, and the similarity ratio of the time was 10 .

\section{b) Details of the bridge model}

As shown in Figs. 13 and 14, the total length of the main girder was $2400 \mathrm{~mm}$, and the height of the tower was $1000 \mathrm{~mm}$. Poly-vinyl-alcohol (PVA) 
Table 7 Similarity ratios

\begin{tabular}{|l|c|r|}
\hline & Dimension & Similarity ratio \\
\hline Acceleration & $l t^{-2}$ & 1 \\
\hline Length & $l$ & 100 \\
\hline Time & $t$ & 10 \\
\hline Density of mass & $\rho$ & 1 \\
\hline Frequency & $t^{-1}$ & 0.1 \\
\hline Velocity & $l t^{-1}$ & 10 \\
\hline Mass & $\rho l^{3}$ & 1000000 \\
\hline Force & $\rho l^{4} t^{-2}$ & 1000000 \\
\hline Weight & $\rho l^{4} t^{-2}$ & 1000000 \\
\hline Weight per unit length & $\rho l^{3} t^{-2}$ & 10000 \\
\hline Area & $l^{2}$ & 10000 \\
\hline Moment of inertia & $l^{4}$ & 100000000 \\
\hline Modulus of elasticity & $\rho l^{2} t^{-2}$ & 100 \\
\hline Flexural rigidity & $\rho l^{6} t^{-2}$ & 10000000000 \\
\hline Tensile rigidity & $\rho l^{4} t^{-2}$ & 1000000 \\
\hline Spring coefficient in sway & $\rho l^{3} t^{-2}$ & 10000 \\
\hline Spring coefficient in rocking & $\rho l^{5} t^{-2}$ & 100000000 \\
\hline
\end{tabular}

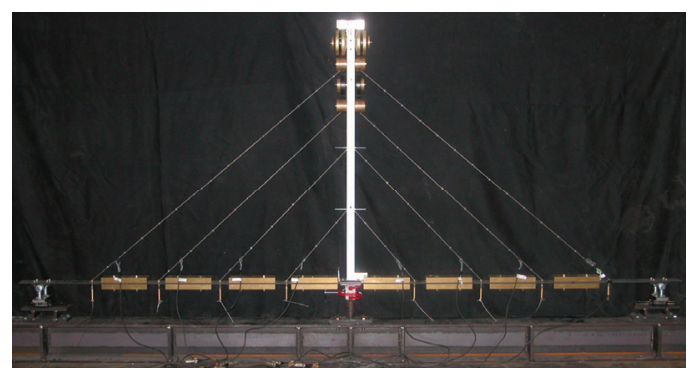

Fig.13 Cable-stayed bridge model.

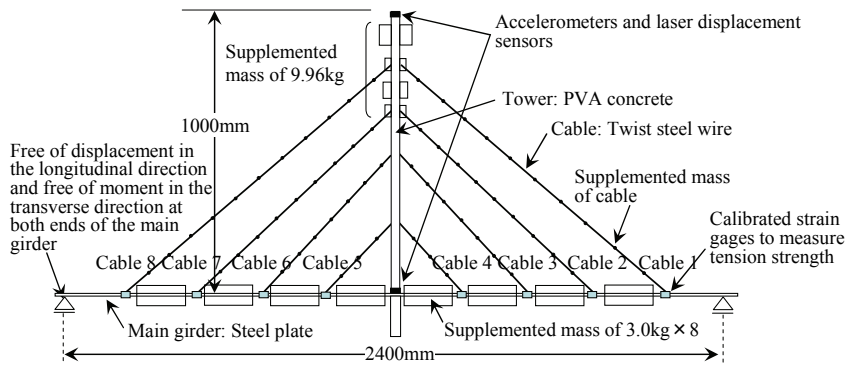

Fig.14 Details of cable-stayed bridge model.

concrete was used as the concrete for the tower. Because the sectional area of the tower was small (30 $\mathrm{mm} \times 30 \mathrm{~mm}$ ), as described below, and the hoop reinforcements could not be used to constrain the core concrete, the PVA concrete was used to effectively constrain the core concrete due to the tension stress provided by fibers in the PVA concrete. The values of the sectional area and the sizes of the longitudinal reinforcements of the tower were determined by referring to the study of fiber-strengthening concrete columns of Sakai et al ${ }^{30)}$ The content of the PVA fibers in the concrete was $2 \%$ by volume. Table 8 shows the mechanical properties of the PVA concrete used for the tower model.

The height and the sectional area of the tower cross-section, and the sizes of the longitudinal reinforcements were determined to satisfy the similarity ratios with respect to length and flexural rigidity.
Table 8 Mechanical properties of the PVA concrete.

\begin{tabular}{|l|l|l|l|l|}
\hline \multicolumn{3}{|c|}{ Compression } & \multicolumn{2}{c|}{ Tension } \\
\hline $\begin{array}{l}\text { Secant } \\
\text { modulus of } \\
\text { elasticity } E_{c} \\
(\mathrm{GPa})\end{array}$ & $\begin{array}{l}\text { Maximum } \\
\text { strength } \sigma_{c} \\
(\mathrm{MPa})\end{array}$ & $\begin{array}{l}\text { Strain at } \\
\text { maximum } \\
\text { strength } \varepsilon_{c}(\%)\end{array}$ & $\begin{array}{l}\text { Stress at initial } \\
\text { cracking } \sigma_{c} \\
(\mathrm{MPa})\end{array}$ & $\begin{array}{l}\text { Ultimate strain } \\
\varepsilon_{u}(\%)\end{array}$ \\
\hline 15.5 & 33.3 & 0.46 & 3.52 & 1.00 \\
\hline
\end{tabular}

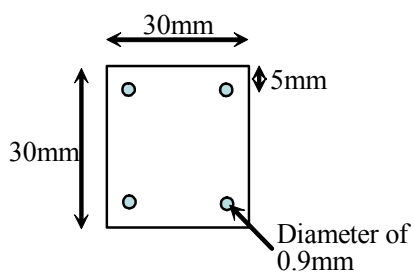

Fig. 15 Cross section of the tower model.

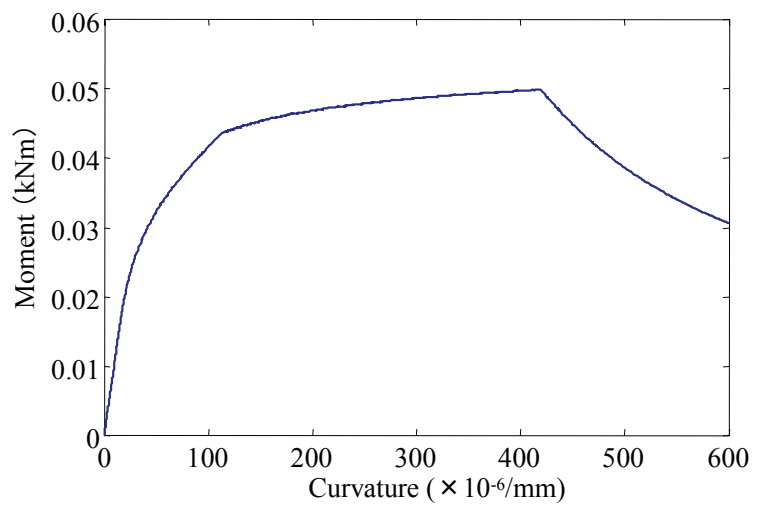

Fig. 16 Moment-versus-curvature relationship at the bottom of the tower model.

The resulting cross-section of the tower is shown in Fig. 15. Its sectional area was $30 \mathrm{~mm} \times 30 \mathrm{~mm}$, and four longitudinal reinforcements $0.9 \mathrm{~mm}$ in diameter with tension strengths of $336 \mathrm{MPa}$ were used. The skeleton of the moment-versus-curvature hysteresis at the bottom of the tower was numerically obtained by modeling the tension stress resulting from the PVA fibers based on the constitutive laws of Shimizu et al. ${ }^{31)}$, as shown in Fig. 16. It seems reasonable to suppose that the cyclic behavior associated with the stress-versus-strain relationship of the used PVA concrete has similar trend as that from the research of Billington and Kesner ${ }^{32)}$, however it needs further consideration in this study since we could not obtain the cyclic behaviour of the tower model experimentally. Brass weights of $9.96 \mathrm{~kg}$ were attached at the top of the tower model, as shown in Fig. 14, to satisfy the similarity ratio with respect to the mass of the tower.

Although the girders of the actual bridge (prototype bridge) were formed of prestressed concrete, for the sake of ease of manufacturing, the girders of the model were steel plates of $50 \mathrm{~mm}$ in width and 6 $\mathrm{mm}$ in height to satisfy the similarity ratio with respect to the flexural rigidity. Eight brass weights of each $3.0 \mathrm{~kg}$ were attached to the girders to satisfy the similarity ratio with respect to the mass of the 
Table 9 Prestressed tension strength of cables.

\begin{tabular}{|c|c|}
\hline Cable No. & Tension $(\mathrm{N})$ \\
\hline 1 & 43.7 \\
\hline 2 & 34.6 \\
\hline 3 & 32.5 \\
\hline 4 & 44.7 \\
\hline 5 & 44.7 \\
\hline 6 & 32.5 \\
\hline 7 & 34.6 \\
\hline 8 & 43.7 \\
\hline
\end{tabular}

girders.

Idealized cables were designed based on the similarity ratio with respect to the force by referring to the tension strength at a permanent strain of $2 \%$; thus, twisted steel wires $1.5 \mathrm{~mm}$ in diameter with a tension strength of $269.5 \mathrm{~N}$ at a permanent strain of $2 \%$ were used for the model cables. In the prototype bridge, the 68 cables are tensioned in parallel at the center line of the girder in the longitudinal direction, then the 34 cables should be idealized in the tests. However the number of cables was reduced from the 34 cables to the 8 ones. The reason for this is that it is quite difficult to perfectly satisfy the similarity ratio for all 34 cables from the viewpoint of the construction of the cable models and the prestressing of the tension strength of the cables.

In spite of the reduction of the number of the cables, to satisfy the similarity associated with the prestressed strength of the cables between the prototype bridge and the model, and asscociated with the moment acting onto the section of the girder with respect to the transverse axis due to the cable tension, the prestressed tension strength of each model cable and its attachment positions to the girder and the tower were determined so that the vertical component of the tension for each cable was the same as the sum of the vertical components of the tensions for the cables provided before reducing the number of cables to 8 , and so that the resulting moment on the girder from the tension of each cable was the same as the sum of the moments on the girder from the tensions of the cables provided before reducing the number of cables to 8 . Table 9 shows the prestressed tension strength of the cables. The cable numbers in Table 9 correspond to those in Fig. 14. The values of the prestressed tension strength in Table 9 are the required ones before the start of the shaking table test. However, because of the difficulty of prestressing the tension for 8 cables, the error of the prestressed tension strength with respect to the required values shown in Table 9 varied from $0.1 \%$ to $6.4 \%$.

This experiment was focused on clarifying the seismic response of the tower and cables. Hence, the pier was idealized by a rigid body made of a circular steel bar $30 \mathrm{~mm}$ in diameter. The free and
Table 10 Natural periods and damping ratios of the bridge model before and after the shaking table tests.

\begin{tabular}{|c|c|c|c|}
\hline Test No. & $\begin{array}{l}\text { Natural period } \\
\text { before the test (sec) }\end{array}$ & $\begin{array}{l}\text { Damping ratio } \\
\text { before the test }\end{array}$ & $\begin{array}{l}\text { Natural period } \\
\text { after the test (sec) }\end{array}$ \\
\hline 1 & 0.318 & 0.00604 & 0.318 \\
\hline 2 & 0.313 & 0.00678 & 0.315 \\
\hline 3 & 0.314 & 0.00877 & 0.353 \\
\hline 4 & 0.322 & 0.00858 & 0.325 \\
\hline 5 & 0.325 & 0.00803 & 0.355 \\
\hline 6 & 0.311 & 0.00949 & 0.312 \\
\hline 7 & 0.312 & 0.00992 & 0.345 \\
\hline 8 & 0.345 & 0.023 & 0.426 \\
\hline 9 & 0.316 & 0.00688 & 0.316 \\
\hline 10 & 0.316 & 0.00594 & 0.316 \\
\hline 11 & 0.316 & 0.00676 & 0.315 \\
\hline 12 & 0.315 & 0.00686 & 0.320 \\
\hline 13 & 0.318 & 0.00638 & 0.318 \\
\hline 14 & 0.314 & 0.00877 & 0.353 \\
\hline 15 & 0.318 & 0.00769 & 0.338 \\
\hline 16 & 0.320 & 0.00835 & 0.320 \\
\hline 17 & 0.320 & 0.00841 & 0.327 \\
\hline
\end{tabular}

the fixed support conditions of the longitudinal, the transverse, and the rotational movements at both ends of the girder were idealized by combining a slider and a bearing.

Acceleration in the tower top and at the tower bottom in the transverse and longitudinal directions is recorded by accelerometers and displacement in the same positions as acceleration is recorded by laser displacement sensors, as shown in Fig. 14. Tension strength of cables is measured by the strain gage attached on the edge of each cable, whose value is related with tension strength before the tests. Sampling frequency at which all data above are recorded is $1000 \mathrm{~Hz}$.

The average values of the dominant natural period and the damping ratio with respect to the transverse direction of the bridge model were computed based on the displacement waveforms at the top of the tower obtained from the free vibration tests. Three free vibration tests were conducted before and after each test. Table 10 shows the computed natural periods before and after the tests and the computed damping ratios before the tests. These natural periods for the bridge model correspond to a natural period of more than $3.0 \mathrm{sec}$ for the actual bridge based on the similarity ratio with respect to time shown in Table 7.

The natural period with respect to the longitudinal direction of the bridge model was evaluated by the Fourier transforms of the acceleration waveforms obtained from the free vibration tests. The results indicate that there were several predominant coupled modes in the period ranging from $0.1 \mathrm{sec}$ to $0.31 \mathrm{sec}$.

\section{(2) Input ground motion for the shaking table test}

Table 11 shows the test cases for the shaking ta- 
Table 11 Shaking table tests.

\begin{tabular}{|c|c|c|c|c|}
\hline $\begin{array}{l}\text { Test } \\
\text { No. }\end{array}$ & $\begin{array}{l}\text { Direction } \\
\text { of shaking }\end{array}$ & Input excitation & Component. & $\begin{array}{l}\text { Amplification } \\
\text { factor of } \\
\text { amplitude }\end{array}$ \\
\hline 1 & \multirow{12}{*}{ TR } & $\begin{array}{l}\text { Simulated waveform at Ji-Lu } \\
\text { Bridge in the } 1999 \text { Chi-Chi, } \\
\text { Taiwan EQ. }\end{array}$ & EW & 1 \\
\hline 2 & & $\begin{array}{l}\text { Simulated waveform at Ji-Lu } \\
\text { Bridge in the } 1999 \text { Chi-Chi, } \\
\text { Taiwan EQ. }\end{array}$ & EW & 2 \\
\hline 3 & & $\begin{array}{l}\text { Simulated waveform at Ji-Lu } \\
\text { Bridge in the } 1999 \text { Chi-Chi, } \\
\text { Taiwan EQ. }\end{array}$ & EW & 3 \\
\hline 4 & & $\begin{array}{l}\text { Simulated waveform at OSK008 } \\
\text { in the anticipated Nankai EQ. }\end{array}$ & EW & 1 \\
\hline 5 & & $\begin{array}{l}\text { Simulated waveform at OSK008 } \\
\text { in the anticipated Nankai EQ. }\end{array}$ & EW & 2 \\
\hline 6 & & $\begin{array}{l}\text { Simulated waveform at OSK008 } \\
\text { in the anticipated Nankai EQ. }\end{array}$ & NS & 1 \\
\hline 7 & & $\begin{array}{l}\text { Simulated waveform at OSK008 } \\
\text { in the anticipated Nankai EQ. }\end{array}$ & NS & 2 \\
\hline 8 & & $\begin{array}{l}\text { Simulated waveform at OSK008 } \\
\text { in the anticipated Nankai EQ. }\end{array}$ & NS & 3 \\
\hline 9 & & $\begin{array}{l}\text { Simulated waveform at OSK003 } \\
\text { in the anticipated Nankai EQ. }\end{array}$ & EW & 1 \\
\hline 10 & & $\begin{array}{l}\text { Simulated waveform at OSK003 } \\
\text { in the anticipated Nankai EQ. }\end{array}$ & NS & 1 \\
\hline 11 & & $\begin{array}{l}\text { Simulated waveform at OSK005 } \\
\text { in the anticipated Nankai EQ. }\end{array}$ & EW & 1 \\
\hline 12 & & $\begin{array}{l}\text { Simulated waveform at OSK005 } \\
\text { in the anticipated Nankai EQ. }\end{array}$ & NS & 1 \\
\hline 13 & \multirow{5}{*}{$\mathrm{TR}+\mathrm{LG}$} & $\begin{array}{l}\text { Simulated waveform at Ji-Lu } \\
\text { Bridge in the } 1999 \text { Chi-Chi, } \\
\text { Taiwan EQ. }\end{array}$ & NS+EW & 1 \\
\hline 14 & & $\begin{array}{l}\text { Simulated waveform at Ji-Lu } \\
\text { Bridge in the } 1999 \text { Chi-Chi, } \\
\text { Taiwan EQ. }\end{array}$ & NS+EW & 2 \\
\hline 15 & & $\begin{array}{l}\text { Simulated waveform at OSK008 } \\
\text { in the anticipated Nankai EQ. }\end{array}$ & NS+EW & 1 \\
\hline 16 & & $\begin{array}{l}\text { Simulated waveform at OSK003 } \\
\text { in the anticipated Nankai EQ. }\end{array}$ & NS+EW & 1 \\
\hline 17 & & $\begin{array}{l}\text { Simulated waveform at OSK005 } \\
\text { in the anticipated Nankai EQ. }\end{array}$ & NS+EW & 1 \\
\hline
\end{tabular}

ble test. Uni-lateral and bi-lateral shaking table tests were conducted using the simulated ground excitation at the site of the Ji-Lu Bridge described in Section 2 and the excitations of the anticipated Nankai earthquake at stations OSK003, OSK005, and OSK008 simulated by Kamae et al. ${ }^{5)}$ The uni-lateral shaking was in the transverse direction of the bridge model, which was subjected to the EW component or the NS component of those excitations. The bilateral shaking was simultaneously in the transverse and longitudinal directions of the bridge model; the transverse direction was subjected to the EW component of the above excitations and the longitudinal direction was subjected to the NS component. The seismic excitations were modified based on the similarity ratios with respect to length and time shown in Table 7.

Fig. 17 shows the time histories of those excitations, and Fig. 18 shows their response spectra. Fig. 18 also shows the seismic response spectra of the bridge model when subjected to the NS component of ground motions recorded at the JMA Kobe Observatory in the 1995 Hyogo-ken Nambu earthquake (Kobe NS) to clarify the difference of the response spectra of long-period ground motions and typical near-field ground motion. From Fig. 18, the acceleration and velocity responses at the natural period of about $0.3 \mathrm{sec}$, which is nearly equal to the dominant period of the bridge model as shown in Table 10, are larger than those at other periods. On the other hand, the displacement responses at the natural period of about $0.3 \mathrm{sec}$ do not become larger than those at other periods.

\section{MECHANISM OF THE SEISMIC RE- SPONSE OF THE BRIDGE MODEL}

\section{(1) Linear seismic response of the bridge model when subjected to the uni-lateral shaking}

Fig. 19 shows the maximum acceleration and displacement responses in the transverse direction at the top of the prototype bridge, when subjected to the simulated seismic excitation at the site of the JiLu Bridge (Test No.1: Ji-Lu Br. EW) and the simulated excitations of the anticipated Nankai earthquake at stations OSK008EW, OSK003EW, and OSK005EW (Test No.4: OSK008EW, No.9: OSK003EW, and No.11: OSK005EW). Associated with all cases above, the seismic responses of the bridge model are in the linear range, where no cracks occur in the tower in the experiments. Thus, Fig. 19 show the cases where the experimental results are scaled up to those for the prototype bridge based on the similarity ratios with respect to length and time shown in Table 7. In addition, to compare the seismic responses of the case subjected to the long-period excitations (OSK003EW, OSK005EW, OSK008EW) with those subjected to the near-field exitation (Kobe NS), Fig. 19 shows the same results when subjected to the Kobe NS exitation from nonlinear seismic analysis, in which the structural modeling of the bridge model is the same as that adopted in Section 3. In the Kobe NS case, the seismic responses of the bridge model are also in the liner range.

From Fig. 19, it indicates that the maximum accelerations in the cases of the Ji-Lu Br. EW, OSK003EW, OSK005EW, and OSK008EW are less than that in the case of the Kobe NS excitation. In contrast, the maximum displacements in the cases of the Ji-Lu Br. EW, OSK003EW, OSK005EW, and OSK008EW are larger than that in the case of the Kobe NS excitation, especially in the case of OSK008EW, where a maximum displacement of $1.35 \mathrm{~m}$ occurs at the top of the tower. This value of maximum displacement corresponds to a maximum drift ratio of $1.35 \%$, which is a large value corresponding with the response level of which seismic behavior of the tower becomes nearly equal to be nonlinear, describing the following figure.

Fig. 20 shows the relationship between the lateral force and the lateral displacement at the top of the 


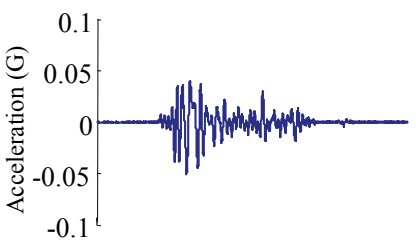

i) EW componen

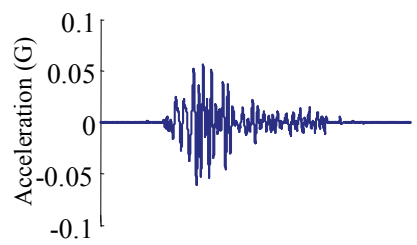

ii) NS component

(a) Simulated ground excitation at the site of the Ji-Lu Bridge

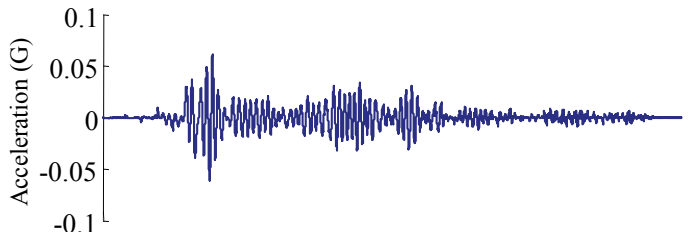

i) EW component

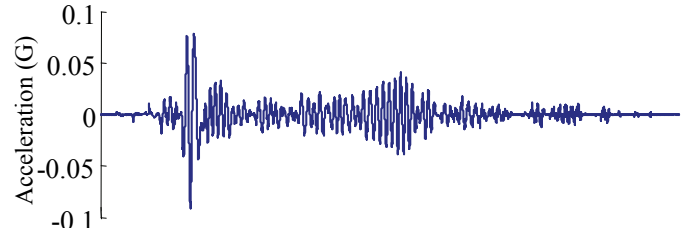

ii) NS component

(b) Simulated ground excitation of the anticipated Nankai earthquake at station OSK008

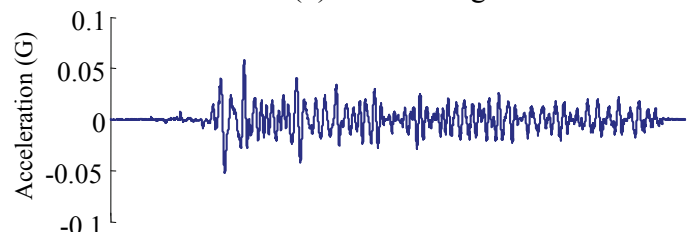

i) EW component

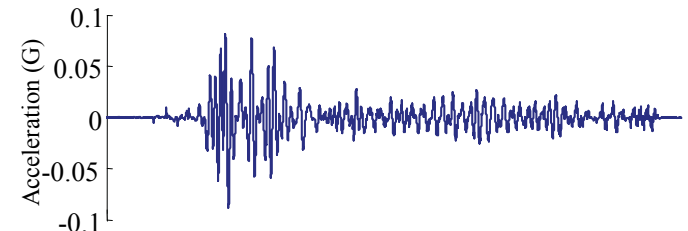

ii) NS component

(c) Simulated ground excitation of the anticipated Nankai earthquake at station OSK003

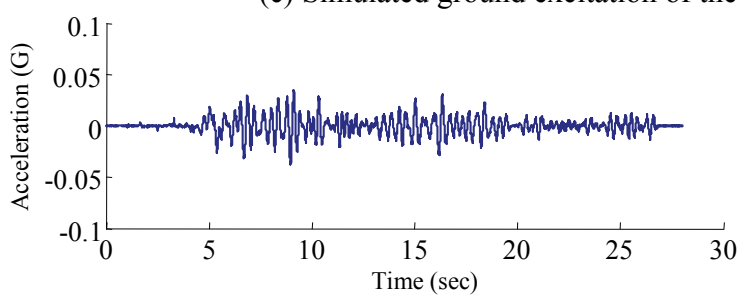

i) EW component

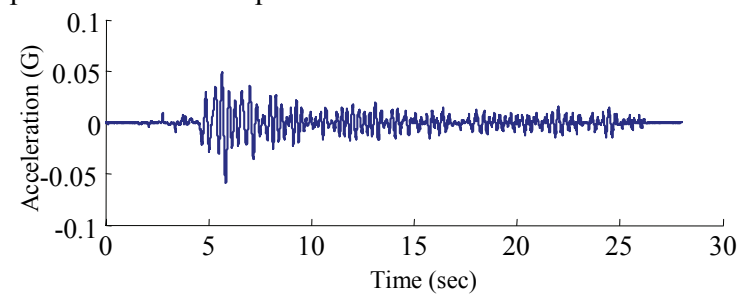

ii) NS component

(d) Simulated ground excitation of the anticipated Nankai earthquake at station OSK005

Fig. 17 Input accelerations used for the shaking table tests.

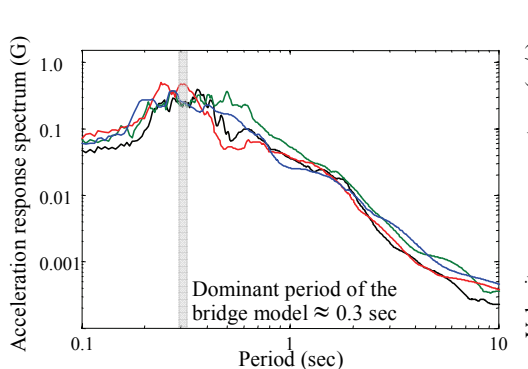

i) Acceleration response spectra

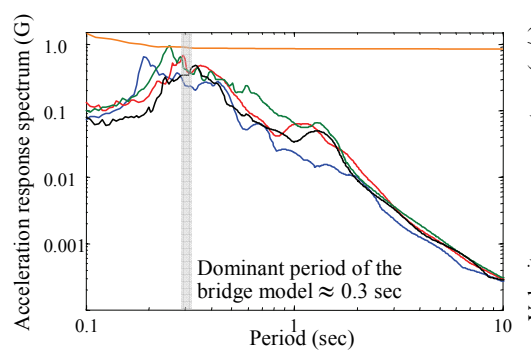

i) Acceleration response spectra

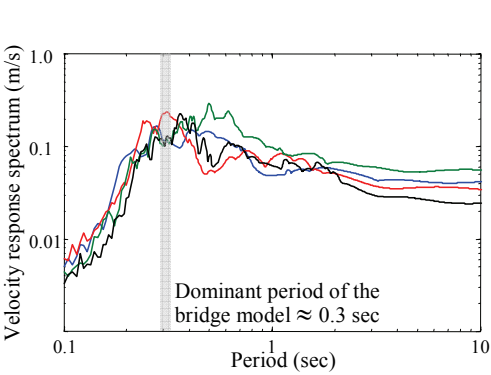

ii) Velocity response spectra

(a) EW component

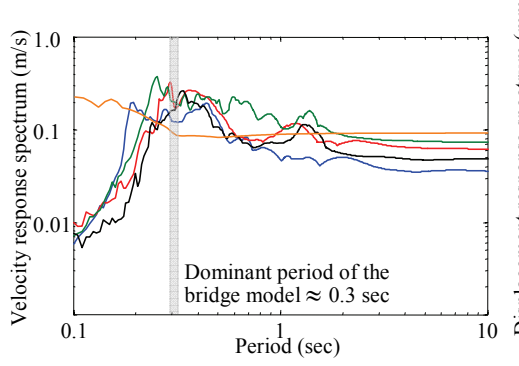

ii) Velocity response spectra

(b) NS component

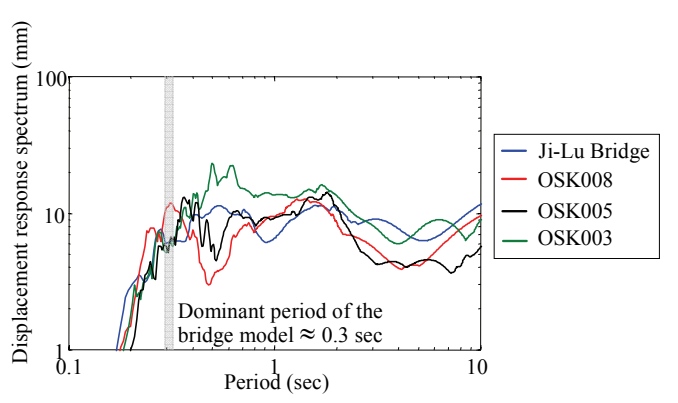

iii) Displacement response spectra

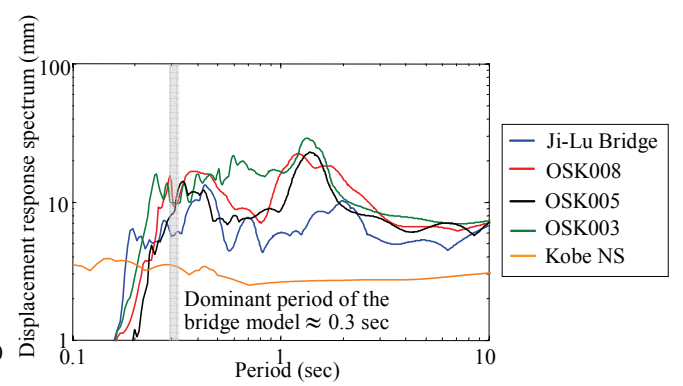

iii) Displacement response spectra

Fig. 18 Response spectra for the bridge model when subjected to input ground motion. 


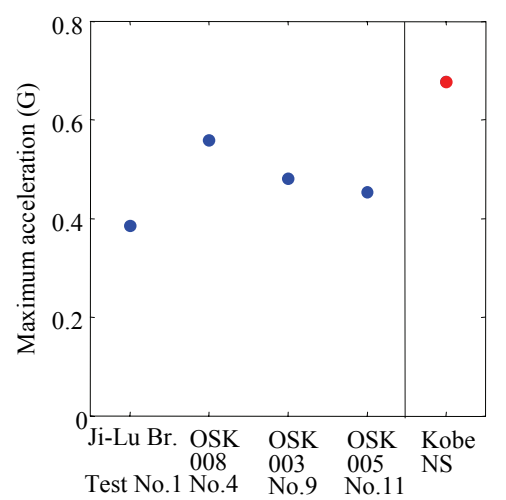

(a) Maximum acceleration response

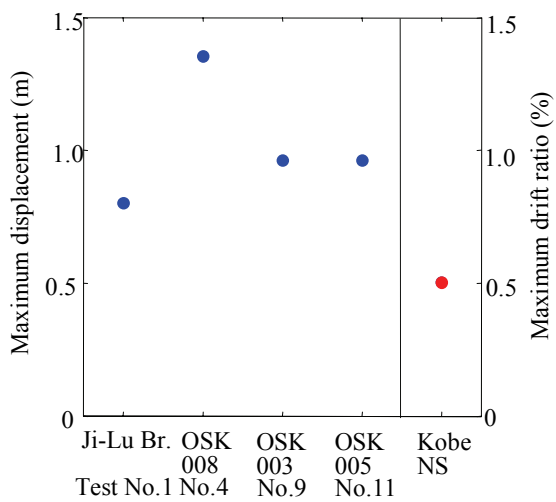

(b) Maximum displacement response

Fig. 19 Maximum acceleration and maximum displacement responses in the transverse direction at the top of the tower.

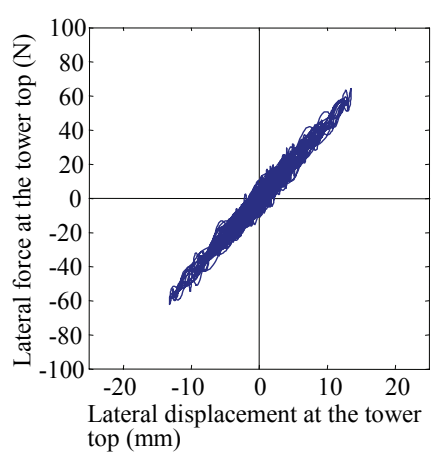

(a) In the case of the excitation equal to the OSK008 EW (Test No.4)

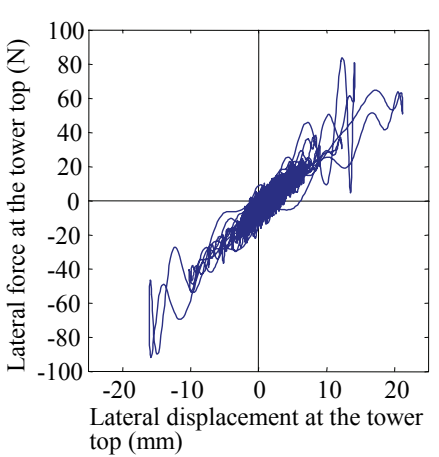

(b) In the case of two times the excitation of the OSK008 EW component (Test No.5)

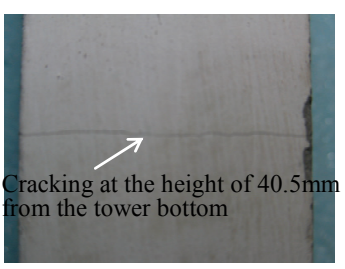

Fig. 20 Lateral force versus lateral displacement relationship at the top of the tower, depending on the amplitudes of excitations.

tower for uni-lateral transverse shaking in the case of the OSK008EW (Test No.4) and two times the excitation of the OSK008 EW component (Test No.5: 2 times-OSK008EW). The former case shows a linear response of the tower, previously shown in Fig. 19, whereas the latter one shows a nonlinear response that causes cracks in the tower model. As mentioned above, although the relationship between the lateral force and the lateral displacement in the case of OSK008EW is limited in the linear range (Fig. 20(a)), its response level reaches almost same one to be nonlinear hysteretic behavior that the case of 2 times-OSK008EW shows (Fig. 20(b)).

The occurrence of larger displacement at the tower top in the cases of the long-period ground motions than that in the case of the Kobe NS excitation, results from the larger displacement response at the tower top in the transverse direction on the 1st mode shown in Fig. 10 (a), due to the matching of the dominant natural period of the bridge model and that of the long-period ground motions, shown in Fig. 18. Thus, even though the acceleration response of the long-period bridge does not become larger within the range of $0.04 \mathrm{G}$ to $0.06 \mathrm{G}$, the displacement response could become larger when subjected to the long-period ground motions, and it is likely that this mechanism causes the nonlinear hysteretic behavior of the tower shown in Fig. 20(b).
(2) Residual displacement at the top of the tower

Fig. 21 shows the displacement responses at the top of the tower for uni-lateral transverse shaking equal to three times the excitation of the simulated ground motion at the Ji-Lu Bridge (Test No.3: 3 times-Ji-Lu Br. EW), 2 times-OSK008EW (Test No. 5), and two times the excitation of the OSK008 NS component (Test No.7: 2 times-OSK008NS). Fig. 21 also shows a comparison of the residual displacement at the top of the tower model with its maximum displacement in the transverse direction. In all cases, a crack occurred in the tower model; the values of the responses resulting from the tests are not scaled up to in Fig. 21.

From Fig. 21, although the maximum displacements at the top of the tower for different ground motions were nearly the same, namely, about 20 $\mathrm{mm}$, the maximum residual displacements at the top of the tower were quite different depending on the excitations applied. Whereas a slight residual displacement of $0.014 \%$ per unit of drift occurred in the case of 3 times-Ji-Lu Br. EW (Test No.3), larger residual displacements of $0.29 \%$ and $0.12 \%$ per unit of drift occurred for the case of 2 times-OSK008EW (Test No.5) and 2 times-OSK008NS (Test No.7), respectively.

For the three cases described above, the relationship between the lateral force and the lateral dis- 

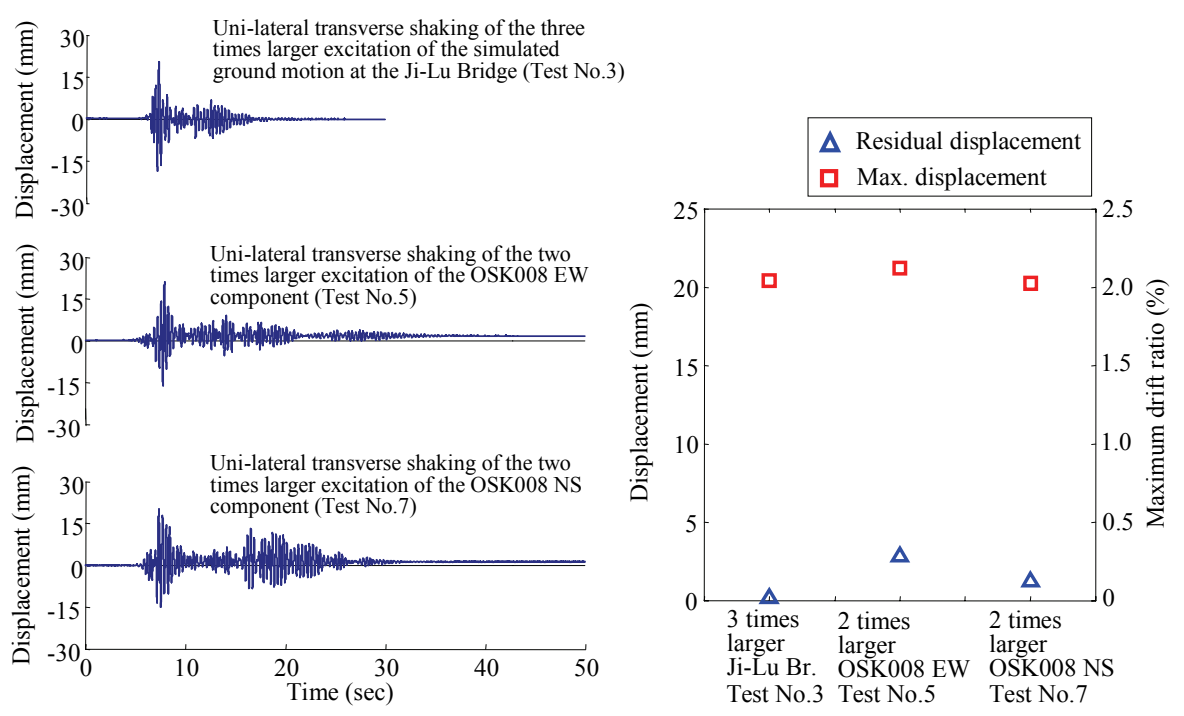

(a) Displacement at the top of the tower in the transverse direction

(b) Comparison of residual displacement with maximum displacement at the tower top Fig. 21 Residual displacement, depending on the duration of the excitation.
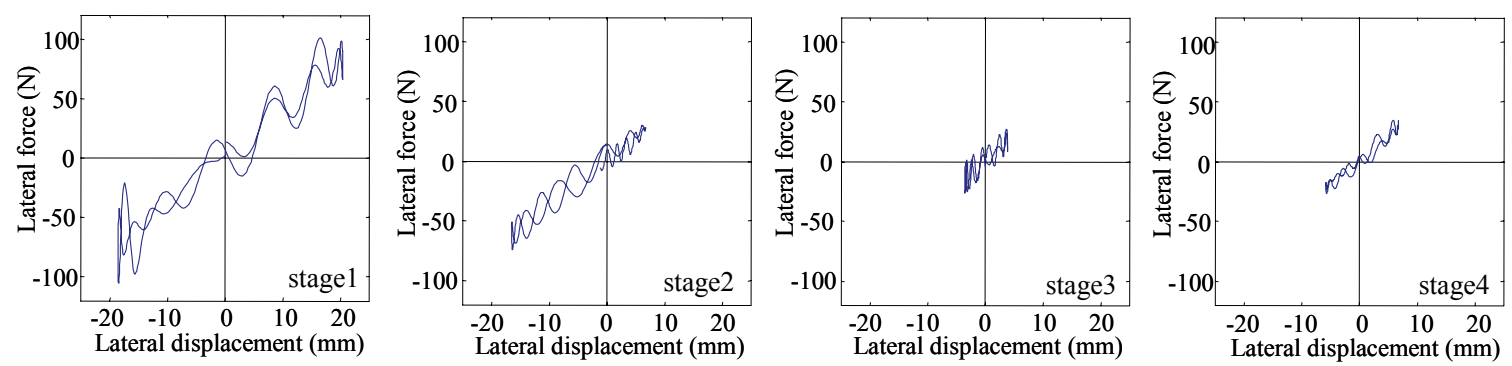

(a) Uni-lateral transverse shaking equal to three times the excitation of the simulated ground motion at the Ji-Lu Bridge (Test No.3)
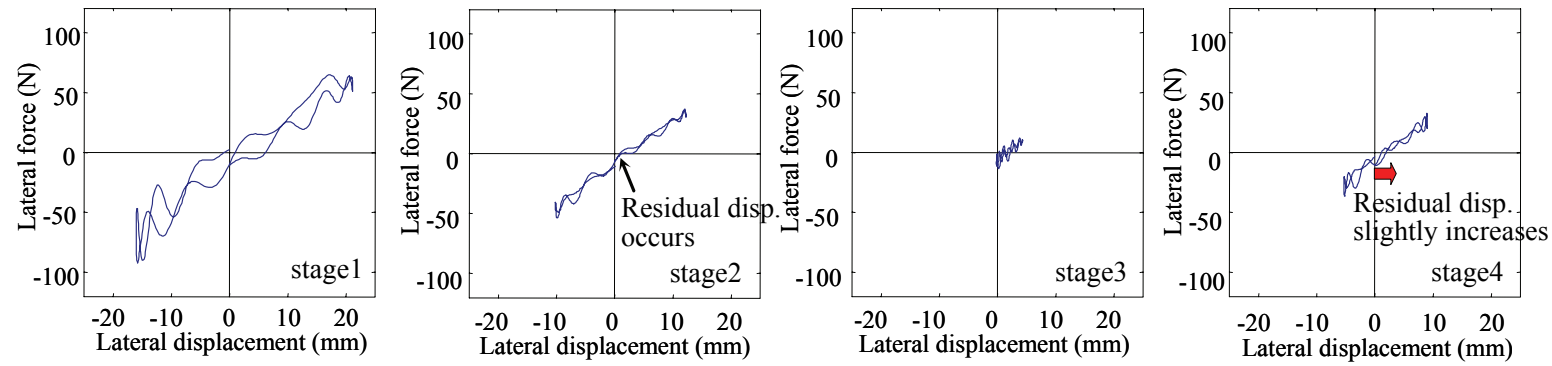

(b) Uni-lateral transverse shaking equal to two times the excitation of the OSK008 EW component (Test No.5)
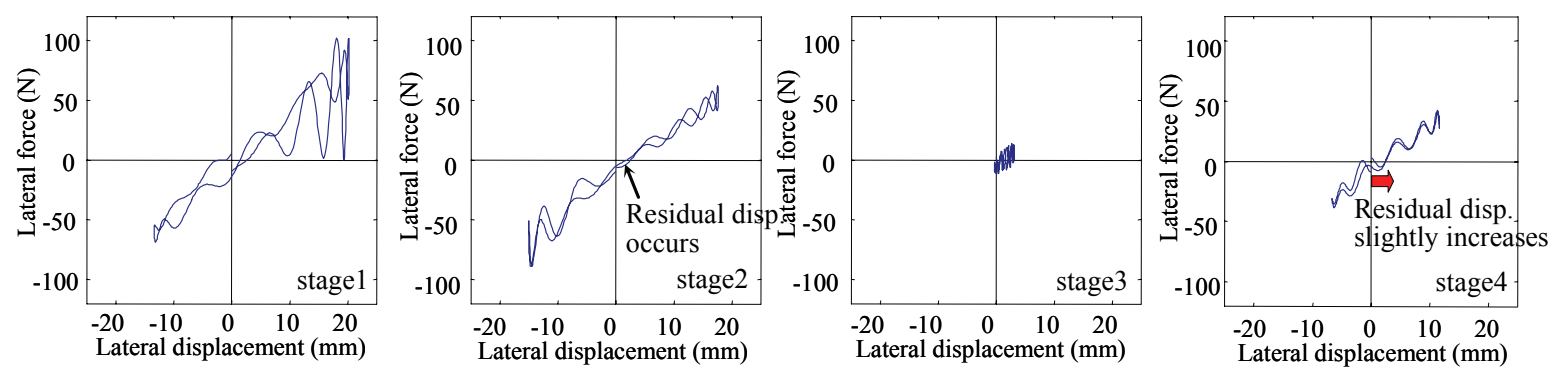

(c) Uni-lateral transverse shaking equal to two times the excitation of the OSK008 NS component (Test No.7)

Fig. 22 Lateral force versus lateral displacement relationship for four different stages in the response time series.

placement was computed for four different stages in the response time series, as shown in Fig. 22: when the maximum displacement occurred when the main large excitation subjected (stage 1), immediately after stage 1 (stage 2), when the displacement response decreased after stage 2 (stage 3 ), and when the displacement response increased after stage 3 due to the subsequent large excitation (stage 4). 


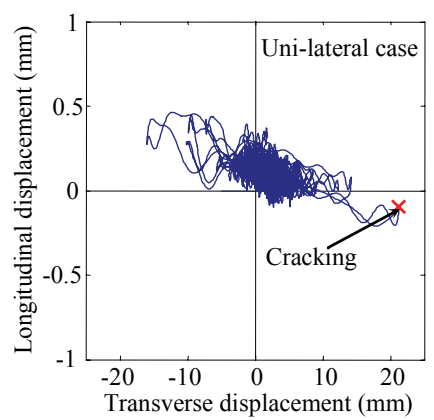

(a) Uni-lateral transverse shaking equal to two times the excitation of the OSK008 EW component (Test No.5)

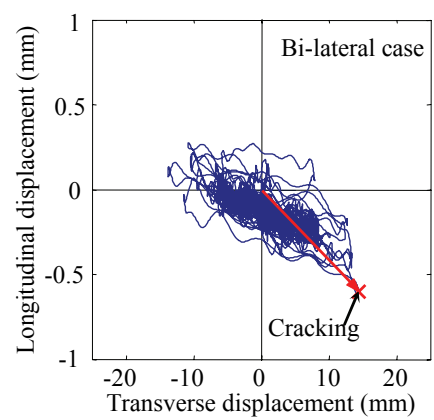

(b) Bi-lateral transverse shaking of OSK008 EW and NS components (Test No.15)

Fig. 23 Comparison of longitudinal displacement versus transverse displacement relationship at the top of the tower, depending on the uni-lateral excitations and the bi-lateral ones.

The residual displacement at the top of the tower did not occur in stage 1 or stage 2 for the case of 3 times-Ji-Lu Br. EW (Test No.3), whereas those occurred in stage 2 for the cases of 2 timesOSK008EW (Test No.5) and 2 times-OSK008NS (Test No.7), and these residual displacements became continuous with those at the end of the displacement waveforms. Focusing on the increase of the residual displacement after stage 2 , in both cases the large displacement response in stage 4 after 15 sec caused a slight increase in the residual displacement at the top of the tower.

The experimental results indicate that the subsequent large excitation after the maximum displacement had no effect on whether the residual displacement at the tower top occurred or not, whereas it had a slight effect on the degree of increasing the residual displacement at the tower top. Because the occurrence of the residual displacement on structural components for the long-period bridge causes the difficulty in the repair process after the bridge is damaged, we must pay more attenetion to the increasing of the residual displacement at the tower subjected to the subsequent large excitation which a long-period ground motion contains.

\section{(3) Uni-lateral shaking versus bi-lateral shaking}

Fig. 23 shows the relationship between the longitudinal displacement and the transverse displacement at the top of the tower for the case of 2 timesOSK008EW (Test No.5) and for bi-lateral transverse and longitudinal shaking equal to the OSK008 EW and NS components (Test No.15: Bi-OSK008). In the case of 2 times-OSK008EW (Test No.5), a maximum displacement of $21.2 \mathrm{~mm}$ occurred at the top of the tower in the transverse direction, which caused a crack in the tower model. In contrast, in the case of Bi-OSK008 (Test No.15), when the transverse displacement of $15.0 \mathrm{~mm}$ was accompanied by the longitudinal one of $0.6 \mathrm{~mm}$, the crack occurred in the tower model.
For the cases described above, the relationships between the longitudinal displacement and the transverse displacement at the bottom and the top of the tower at the maximum displacement, 4 waves before the maximum displacement, and 1 wave after the maximum displacement, were investigated; the results, based on wave length units, are shown in Figs. 24 and 25.

In the case of 2 times-OSK008EW (Test No.5), the phase shift of the transverse response at the bottom and the top of the tower can be clearly observed in Fig. 24; the transverse displacement of the tower top increased 3 to 4 waves after the displacement of the tower bottom increased. In the case of $\mathrm{Bi}$ OSK008 (Test No.15), the longitudinal displacement at the tower bottom varied by the range of $\pm 0.5 \mathrm{~mm}$ that was larger than that in the case of 2 times-OSK008EW by the range of $\pm 0.2 \mathrm{~mm}$, and this caused the variation of the longitudinal displacement at the tower top and the coupled vibration between the longitudinal and transverse directions at the tower top. As a result of this, a large displacement vector was excited between the longitudinal and transverse directions at the tower top shown in Fig. 23(b); this caused the cracking of the tower. Although the evidence is not compelling, it seems likely that the 2 nd mode of the bridge model, which is the anti-symmetry one in the longitudinal direction shown in Table 6 and Fig. 10(b), contributes the displacement response of the tower in the longitudinal direction and thus to couple the vibration between the longitudinal and transverse directions at the tower top. This is because the 2nd mode period of the bridge model could be assumed to becomes more than $1.0 \mathrm{sec}$ when the 1st mode period reaches to more than $3.0 \mathrm{sec}$. Therefore when the longperiod bridge is subjected to a long-period ground motion, the coupling of the vibration between the 1 st mode and others might occurs at the range of the natural period of more than $1.0 \mathrm{sec}$. 


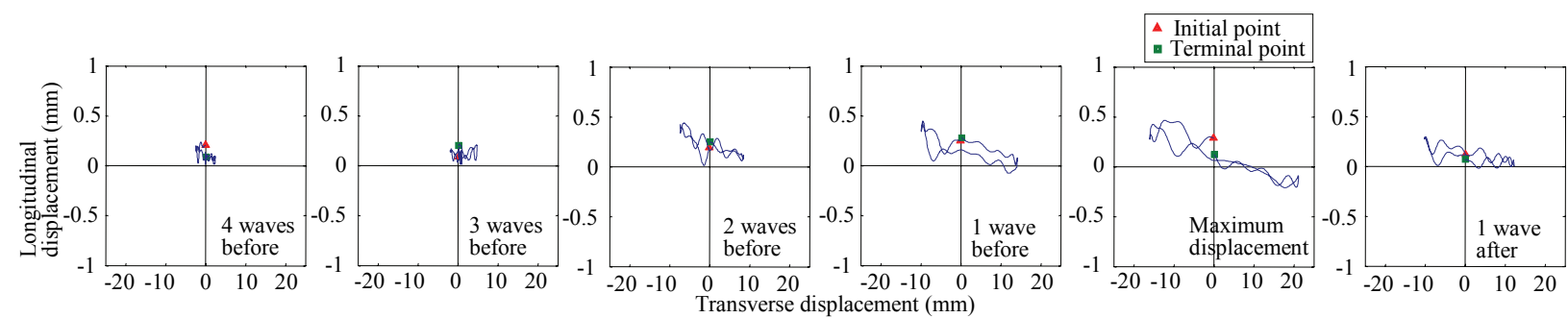

(a) At the top of the tower

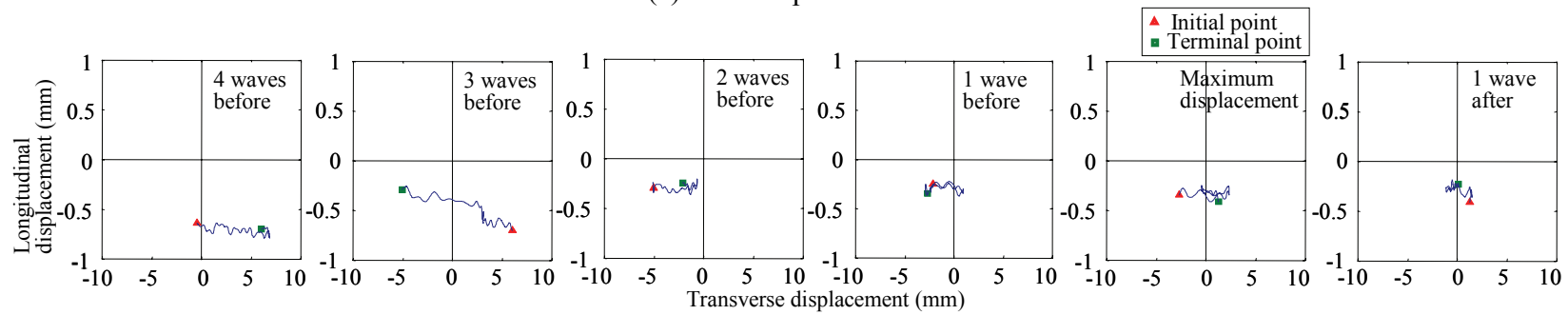

(b) At the bottom of the tower

Fig. 24 Relationship between longitudinal displacement and transverse displacement for uni-lateral transverse shaking equal to two times the excitation of the OSK008 EW component (Test No.5).
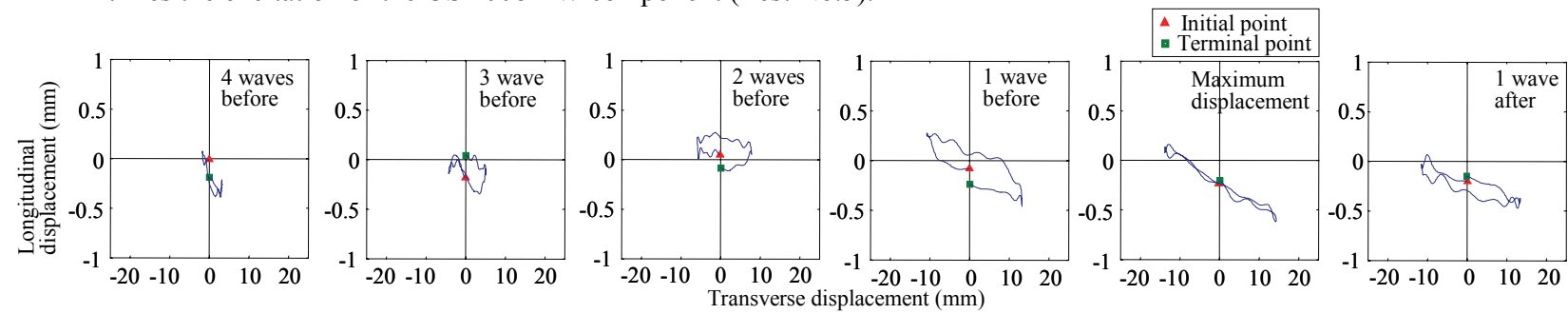

(a) At the top of the tower
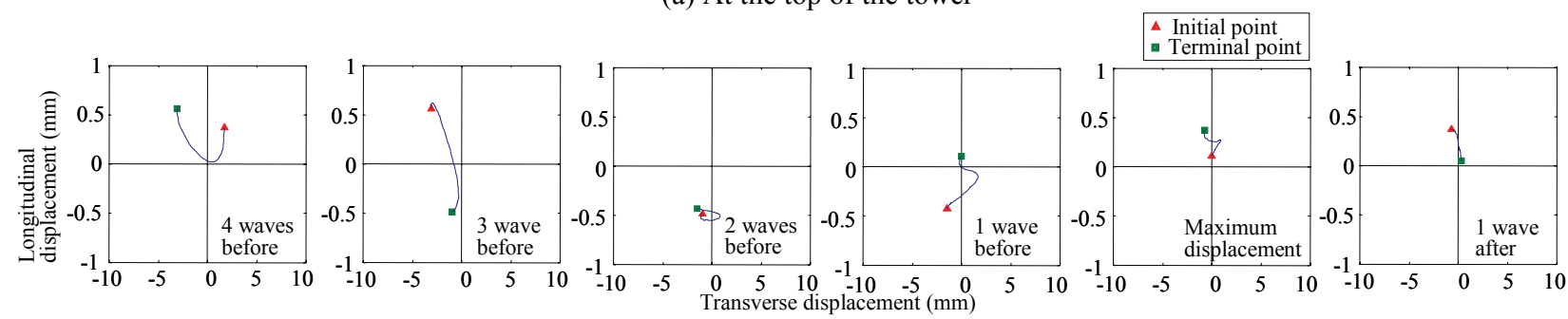

(b) At the bottom of the tower

Fig. 25 Relationship between longitudinal displacement and transverse displacement for bi-lateral transverse shaking in the case of the OSK008 EW and NS components (Test No.15).

\section{(4) Coupled seismic response between the tower and the cables}

Fig. 26 shows the tension variation of the cables, and the relationship between the prestressed tension strength and the maximum tension strength for the case of Bi-OSK008 (Test No.15).

The large maximum displacement of the tower top in the transverse direction, that is $15.0 \mathrm{~mm}$ (Figs. 23(b), 26(b)), caused a drift in the variation of each cable tension (Fig. 26(a)), and the damage to the tower model caused a maximum tension variation of $19.8 \%$ in cable 1 , which was positioned closest to the tower, and a maximum tension variation of $9.24 \%$ in cable 4 , which was positioned farthest from the tower (Fig. 26(c)).

This indicates that the large displacement vector at the tower top with the coupling of the vibration modes in the longitudinal and transverse directions described previously, induced the tension variation of the cables. This resulted from the large transverse component of the displacement vector at the tower top due to the matching of the dominant natural period of the bridge model and that of the long-period ground motions, shown in Fig. $\mathbf{1 8}$ as well as in the case of the uni-lateral shaking. It is possible that larger tension variation of the cables is induced when the transverse displacement at the tower top becomes larger, thus the coupling response between the tower and the cables should be carefully given attention to when subjected to the long-period ground motion. 


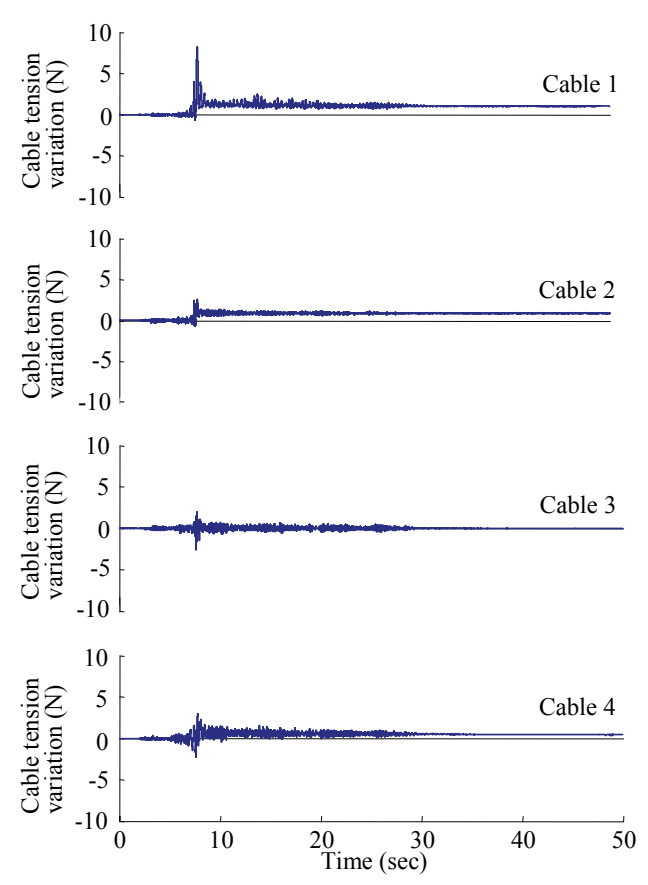

(a) Variation of cable tension strength

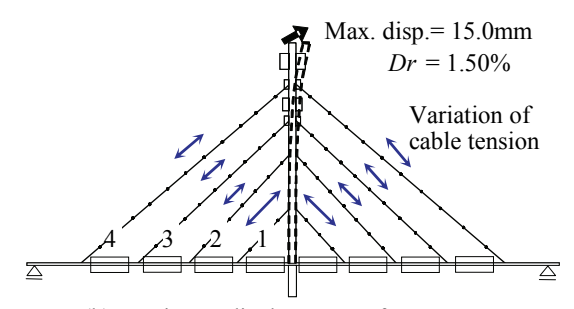

(b) Maximum displacement of tower top

in the transverse direction

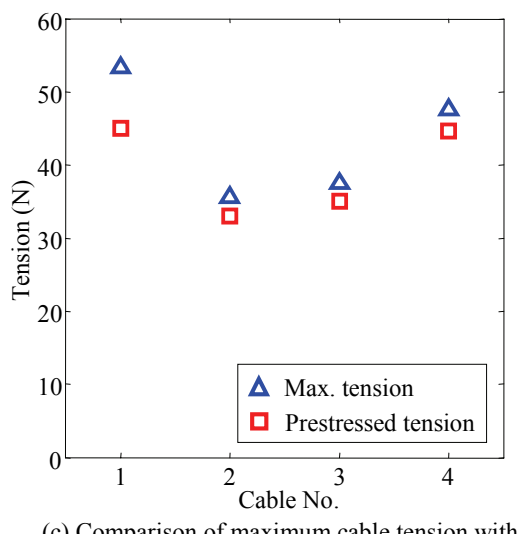

(c) Comparison of maximum cable tension with prestressed cable tension

Fig. 26 Seismic response of the cables for bi-lateral shaking in the case of the OSK008 excitation (Test No.15).

\section{CONCLUSIONS}

In this study the mechanisms associated with the seismic response of a PC cable-stayed bridge when subjected to a long-period ground motion were clarified based on seismic response analyses and shaking table tests considering the similarity law. This study defined the 'long-period' of ground motions as the period of more than $2.0 \mathrm{sec}$ or $2.5 \mathrm{sec}$. The natural period of the subject structures was from $2.0 \mathrm{sec}$ to $3.0 \mathrm{sec}$. The simulated long-period ground motions in the 1999 Chi-Chi, Taiwan earthquake and the anticipated Nankai earthquake were used as the input ground motions in the numerical analyses and the shaking table tests. The following conclusions were obtained from the study:

1) The seismic excitation at the site of the Ji-Lu Bridge, which was damaged in the 1999 Chi-Chi, Taiwan earthquake, was simulated by the finite differential method. Using the simulated longperiod ground motions, the damage to the bridge was assessed from the nonlinear seismic analysis. From this analysis, damage beyond the crack level occurred at the bottom of the tower. However, yielding-level damage did not occur at the bottom of the tower, although yielding of the longitudinal reinforcements and spalling-off of the cover concrete actually occurred. The reason for this discrepancy is that the simulated excitation at the site of the Ji-Lu Bridge contained long-period components of more than $2.0 \mathrm{sec}$, and its seismic response around the period of $2.005 \mathrm{sec}$, which is the dominant natural period of the bridge, was not amplified.

2) From the tests, larger maximum displacements were found at the tower top for the long-period excitations compared with that obtained from the seismic response analysis using the JMA Kobe record (near-field excitation). This resulted from larger displacement response at the tower top in the transverse direction, which maximum drift ratio becomes more than $1 \%$, depending on the 1 st mode of the bridge model, due to the matching of the dominant natural period of the bridge model and that of the long-period ground motions. Thus, even though the acceleration response of the longperiod bridge is not amplified in the range of about $0.05 \mathrm{G}$, the displacement response could become larger when subjected to the long-period ground motions. Although this mechanism is qualitatively quite reasonable based on linear vibration theory, it is more important to note that this mechanism may cause the nonlinear hysteretic behavior of the tower bottom and the exceeding tension variation of the cables.

3) The subsequent large excitation after the maximum displacement at the tower top did not affect the occurrence of the residual displacement of the tower, whereas it slightly affected the degree of increasing the residual displacement. The occurrence of the residual displacement on structural components for the long-period bridge causes the difficulty in the repair process after the bridge is damaged, then we must pay more attenetion to the increasing of the residual displacement at the tower subjected to the subsequent large excitation 
of the long-period ground motion.

4) It seems likely that the 2 nd mode of the bridge model, which was the anti-symmetry one in the longitudinal direction, contributed the displacement response of the tower in the longitudinal direction and thus to couple the vibration between the longitudinal and transverse directions at the tower top. This excited a large displacement vector in the longitudinal and transverse directions at the tower top; this caused the cracking of the tower. Therefore when the long-period bridge is subjected to a long-period ground motion, the coupling of the vibration between the 1st mode and others might occurs at the range of the natural period of more than $1.0 \mathrm{sec}$, which is relatively higher natural period than that of the other structural-typed bridges.

5) Above large displacement vector at the tower top with the coupling of the vibration modes in the longitudinal and transverse directions induced the tension variation of the cables. Since it is possible that larger tension variation of the cables is induced when the transverse displacement at the tower top becomes larger, the coupling response between the tower and the cables should be given much attention to when subjected to the longperiod ground motion.

ACKNOWLEDGMENT: This research was sponsored by the National Research Institute for Earth Science and Disaster Prevention (NIED) under a grant provided for seismic experimental research on bridges titled 'International Joint Model Research for the Application of the Full-Size ThreeDimensional Vibration Destruction Facility (EDefense)'. The authors deeply appreciate research information and valuable assistance provided by Dr. H. Sekiguchi at the Active Fault Research Center, National Institute of Advanced Industrial Science and Technology, regarding the numerical simulations of the ground motion at the Ji-Lu Bridge, and the valuable assistance and support of Dr. S. Aoi and Dr. H. Fujiwara at NIED, regarding the finite differential modeling for the simulation of the longperiod seismic excitations. The authors are also deeply grateful for research information and valuable assistance provided by Professor K. Kosa and Mr. H. Abe at the Kyushu Institute of Technology, Dr. K. Tasaki at Nippon Engineering Consultants Co., Ltd., Mr. H. Ukon at the Hyogo Earthquake Engineering Research Center, NIED, and Dr. M. Yabe at Chodai, Ltd., regarding the modeling of the PC cable-stayed bridge. The authors also specially thank Professor K. Kamae and Dr. H. Kawabe at Research Reactor Institute, Kyoto University, for providing the simulated waveforms of the antici- pated Nankai earthquake. Finally, we are grateful to Dr. A. Numata, Mr. T. Ikeda, Mr. K. Taguchi and the members of Disaster Prevention R\&D Research Institute, Tobishima Corporation, for the use of experimental facilities, and for valuable assistance and support.

\section{REFERENCES}

1) For instance, Irikura, K.: Long-Period Ground Motions from Devastating Great Earthquakes and Action Plans for Earthquake Disaster Mitigation, Chikyu Monthly, No.55, pp. 6-16, 2006 (in Japanese).

2) Kawashima, K., Iemura, H., Shoji, G. and Iwata, S.: Damage of Transportation Facilities in the Chi Chi, Taiwan Earthquake, Technical Report on TIT Earthquake Engineering Research Group, TIT/EERG 99-8, 1999 (in Japanese).

3) Kosa, K., Takahashi, Y., Yamaguchi, E., and Nomura, T.: Analysis of Bridges Damaged by Seismic Motion in the ChiChi Earthquake, Bridges and Foundations, No. 9, pp. 79-86, 2002 (in Japanese).

4) Tasaki, K., Kosa, K., Ikeda, T. and Ogo, M.: Detailed Investigation of PC Cable-Stayed Bridge (Ji-Ji-Da Bridge) Damaged to the Taiwan Chi-Chi Earthquake, Journal of Structural Engineering, JSCE, Vol.50A, pp. 487-494, 2004 (in Japanese).

5) Kamae, K., Kawabe, H. and Irikura, K.: Strong Ground Motion Prediction for Huge Subduction Earthquakes Using a Characterized Source Model and Several Simulation Techniques, 13th World Conference on Earthquake Engineering, Vancouver, B.C., Canada, Paper No. 655 (CD-ROM), 2004.

6) Otsuka, H., Somerville, P.G. and Sato, T.: Estimation of Broadband Strong Ground Motions Considering Uncertainty of Fault Parameters, JSCE Journal of Structural and Earthquake Engineering, No. 584, I-42, pp. 185-200, 1998 (in Japanese).

7) Komori, K., Kikkawa, H., Odagiri, N., Kinoshita, T., Mizoguchi, T., Fujino, Y. and Yabe, M.: Basic Principles and Design Ground Motions in Seismic Retrofit Design of Large Cable-Supported Bridges on the Tokyo Metropolitan Expressway, JSCE Journal of Structural and Earthquake Engineering, No. 794, I-72, pp. 1-19, 2005.7 (in Japanese).

8) Nazmy, A. S. and Abdel-Ghaffar, A. M.: Non-Linear Earthquake-Response Analysis of Long-Span Cable-Stayed Bridges: Theory, Earthquake Engineering and Structural Dynamics, Vol. 19, pp. 45-62, 1990.

9) Nazmy, A. S. and Abdel-Ghaffar, A. M.: Non-Linear Earthquake-Response Analysis of Long-Span Cable-Stayed Bridges: Applications, Earthquake Engineering and Structural Dynamics, Vol. 19, pp. 63-76, 1990.

10) Vilaverde, R. and Martin, S. C.: Passive Seismic Control of Cable-Stayed Bridges with Damped Resonant Appendages, Earthquake Engineering and Structural Dynamics, Vol. 24, pp. 233-246, 1995.

11) Kawashima, K., Unjoh, S., and Tunomoto, M.: Estimation of Damping Ratio of Cable-Stayed Bridges for Seismic Design, Journal of Structural Engineering, ASCE, Vol. 119, No. 4, pp. 1015-1031, 1993.

12) Kitazawa, M., Ishizaki, H., Emi, S. and Nishimori, K.: Characteristics of Earthquake Responses and Aseismic Design on the Long-Period Cable-Stayed Bridge (Higashi-Kobe Bridge) with All Free Movable Shoes in Longitudinal Direction, JSCE Journal of Structural and Earthquake Engineering, No. 422, I-14, pp. 343-352, 1990 (in Japanese).

13) Tai, J.C., and Liou, Y.Y.: Retrofit on Ji-Lu Cable Stayed 
Bridge after 921 Chi-Chi Earthquake, Proceedings of the Second International Workshop on Mitigation of Seismic Effects on Transportation Structures, National Center for Research on Earthquake Engineering, Taipei, Taiwan, R.O.C., pp. 65-79, 2000.

14) Sekiguchi, H. and Iwata, T.: The Source Process of the 1999 Chi-Chi, Taiwan, Earthquake in Semi-Long Period (220s), Active Fault and Old Earthquake Research Report, No. 1, pp. 315-324, 2001 (in Japanese).

15) Chung, J-K. and Yeh, Y.T.:Shallow Crustal Structure from Short-Period Rayleigh-Wave Dispersion Data in Southwestern Taiwan, Bulletin of the Seismological Society of America, Vol. 87, No. 2, pp. 370-382, 1997.

16) Ido, Y. and Shoji, G.: Evaluation of Ground Motions at the Site of the Ji-Lu Bridge in the 1999 Chi-Chi, Taiwan Earthquake, Proceedings of the 8th Symposium on Ductility Design Method for Bridges, JSCE, pp. 441-446, 2005 (in Japanese).

17) Tokimatsu, T. and Sekiguchi, T.: S wave Velocity Structure of the Observatory Stations in the 1999 Chi-Chi, Taiwan Earthquake estimated from Microwave Observation and its Effect of the Structural Seismic Damage, Journal of Structural and Construction Engineering, Transaction AIJ, No. 550 , pp. 65-70, 2001 (in Japanese).

18) Aoi, S. and Fujiwara, H.: 3-D Fourth-Order FiniteDifference Seismograms Using Discontinuous Grids, Proceedings of the Tenth Japan Earthquake Engineering Symposium, Vol. 1, pp. 875-880, 1998 (in Japanese).

19) Aoi, S. and Fujiwara, H.: 3-D Finite Difference Method Using Discontinuous Grids, Bulletin of the Seismological Society of America, Vol. 89, pp. 918-930, 1999.

20) Graves, R.W.: Simulating Seismic Wave Propagation in 3D Elastic Media Using Staggered-Grid Finite Differences, Bulletin of the Seismological Society of America, Vol. 86, No. 4, pp. 1091-1106, 1996.

21) Levander, A.R.: Fourth-Order Finite-Difference $P-S V$ Seismograms, Geophysics, Vol. 53, No. 11, pp. 1425-1436, 1988.

22) Buell, J.C.: A Hybrid Numerical Method for ThreeDimensional Spatially-Developing Free-Shear Flows, Journal of Computational Physics, Vol.95, pp. 313-338, 1991.

23) Takenaka, H.: Computational Methods for Seismic Wave Propagation in Complex Subsurface Structures, Journal of the Seismological Society of Japan, Vol. 46, pp. 191-205, 1993 (in Japanese).

24) Cerjan, C., Kosloff, D., Kosloff, R., and Reshef, M.: A Nonreflecting Boundary Condition for Discrete Acoustic and Elastic Wave Equations, Geophysics, Vol. 50, No. 4, pp. 705708, 1985.

25) Clayton, R. and Engquist, B.: Absorbing Boundary Conditions for Acoustic and Elastic Wave Equations, Bulletin of the Seismological Society of America, Vol. 67, No. 6, pp. 15291540, 1977.

26) Lee, W.H.K., Shin, T.C., Kuo, K.W., and Chen, K.C.: CWB Free-Field Strong-Motion Data from the 921 Chi-Chi Earthquake: Volume 1. Digital Acceleration Files on CD-ROM, Pre-Publication Version, Seismology Center, Central Weather Bureau, Taipei, Taiwan, 1999.

27) Ranbiner, L.R., McClellan, J.H. and Parks, T.W.: FIR Digital Filter Design Techniques Using Weighted Chebyshev Approximation, Proceedings of the IEEE, Vol. 63, No. 4, pp. 595-610, 1975.

28) Takeda, T., Sozen, M. A. and Nielsen, N. N. : Reinforced Concrete Response to Simulated Earthquakes, Proceedings of 3rd Japan Earthquake Symposium, pp.357-364, 1970.

29) Abe, H.: Damage Assessment of Ji-Ji-Da Bridge (PC Cable-Stayed Bridge) suffered from the 1999 Chi-Chi, Taiwan Earthquake, Undergraduate Thesis, Kyushu Institute of Technology, 2004 (in Japanese).

30) Sakai, Y., Tanaka, T., Shiino, A., Tokui, N., Yamauchi, N., Sanada, Y., Nakano, Y., Suwa, H. and Fukuyama, H.: Simplified Vibration Experiment of RC Structure subjected to Various Input Ground Motions, Proceedings of the JAEE Annual Meeting-2004, pp. 424-425, 2004 (in Japanese).

31) Shimizu, K., Ujiie, T., Kanakubo, T. and Hikita, T.: Evaluation of Shear Capacity of PVA-ECC Beam, JCI Annual Convention Proceedings, Vol. 27, No. 2, pp. 1333-1338, 2005 (in Japanese).

32) Billington, S.L. and Kesner, K.E.: Cyclic Response of Ductile Fiber-Reinforced Cement-Based Composites, Proceedings of the Fourth International Workshop on High Performance Fiber Reinforced Cement Composites, HPFRCC4, Ann Arbor, USA, pp. 363-378, 2003.

(Received April 24, 2007) 